\title{
LOST IN TRANSLATION: \\ INCREASING ENGAGEMENT BETWEEN ANGEL INVESTORS AND IMMIGRANT STARTUPS IN THE CANADIAN ENTREPRENEURIAL ECOSYSTEM
}

\author{
by \\ Erina Shirai \\ Honours BA, University of Toronto, Toronto, 2015 \\ A Thesis
presented to Ryerson University
in partial fulfillment of the
requirements for the degree of
Master of Science in Management
in the program of Master of Science in Management
}

Toronto, Ontario, Canada, 2019

(C) Erina Shirai, 2019 


\section{Author's Declaration for Electronic Submission of a Thesis}

I hereby declare that I am the sole author of this thesis. This is a true copy of the thesis, including any required final revisions, as accepted by my examiners.

I authorize Ryerson University to lend this thesis to other institutions or individuals for the purpose of scholarly research.

I further authorize Ryerson University to reproduce this thesis by photocopying or by other means, in total or in part, at the request of other institutions or individuals for the purpose of scholarly research.

I understand that my thesis may be made electronically available to the public. 


\title{
LOST IN TRANSLATION: \\ INCREASING ENGAGEMENT BETWEEN \\ ANGEL INVESTORS AND IMMIGRANT STARTUPS IN THE \\ CANADIAN ENTREPRENEURIAL ECOSYSTEM
}

\author{
Erina Shirai \\ Master of Science in Management \\ Specialization in Entrepreneurship \& Strategy \\ Ryerson University 2019
}

\begin{abstract}
Immigrant entrepreneurs are an important and growing segment of Canada's startup scene. They contribute to the Canadian economy and lower unemployment rates by creating job opportunities through their ventures. However, they face a challenge in receiving funding from local investors in the initial stages of their startup. Angel investors are experienced professionals with an extensive network in the entrepreneurial ecosystem who specialize in early stage funding. Increasing engagement between Angels and immigrant entrepreneurs can create greater opportunities for the immigrant community in Canada and help Angels diversify their portfolio. The objective of this research is to adapt the Investment Decision Making Criteria for Angels (IDMCA) to analyze the factors that influence an Angel's decision making process, and determine whether these factors are moderated by an entrepreneur's immigrant status. Results from the study have shown that the Passion \& Commitment (P\&C), Integrity \& Trust (I\&T), and Open-mind \& Adaptability (O\&A) are important factors for an Angel's decision making in respect to immigrant startups, whereas Industry Experience (IE), Track Record (TR), and Technology Knowledge (TK) are not important factors.
\end{abstract}




\section{Acknowledgements}

I would like to take this opportunity to thank Dr. Howard Lin for his constant guidance, encouragement, and patience throughout the biggest chapter of my academic career. Without your support, this thesis would not have been possible. You have provided me with great confidence to embark on a career in entrepreneurship.

To my examination committee, Dr. James Tiessen, Dr. Carlyle Farrell, and Dr. Deborah De Lange, thank you for your invaluable feedback as well as your support prior to the defense.

Words cannot describe my gratitude for my family and friends. I would not be standing here today with a completed thesis without your love and encouragement throughout the program. To my mother and father who constantly push me to my fullest potential, I am forever grateful and I am determined to make you proud in the next chapter of my life. Thank you for being amazing role models. Thank you to Andre for picking me up whenever I needed someone to lean on during this journey, and to the Fecks for always making me laugh even during the hardest times.

I would also like to thank the National Angels Capital Organization and the Angel investors and immigrant entrepreneurs who have provided their time to participate in my study. Your contribution to this research has been invaluable, and I appreciate your enthusiasm to share your experience.

Thank you to the Ted Rogers School of Management for providing me with this opportunity to work with amazing professors and allowing me to pursue an area of research that combines my passion for entrepreneurship and the immigrant community in Canada. 


\section{TABLE OF CONTENTS}

Author's Declaration for Electronic Submission of a Thesis...............................ii

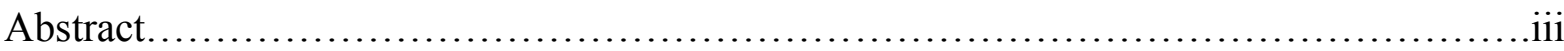

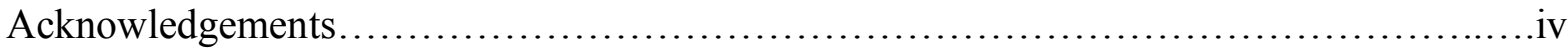

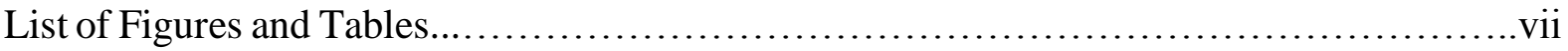

Chapter 1. Introduction............................................................

Chapter 2. Research Questions and Goals..............................................

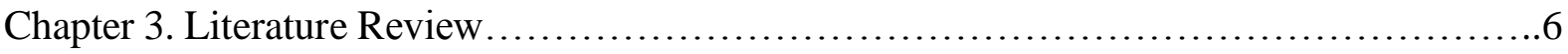

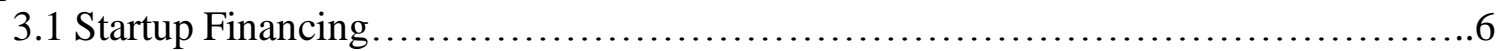

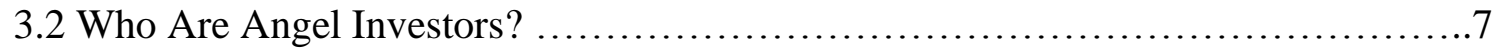

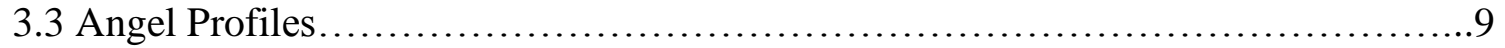

3.3.1 Angel Profiles.................................................... 9

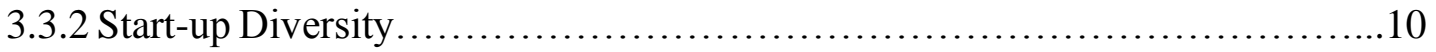

3.3.3 Investment Trends....................................................

3.4 Angel Investment Operations.................................................. 12

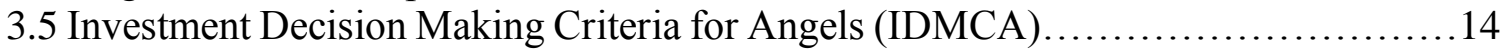

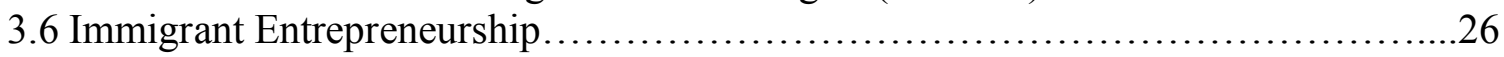

Chapter 4. Research Propositions..................................................29

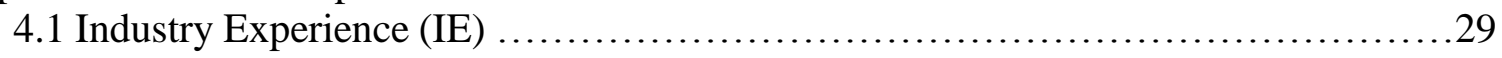

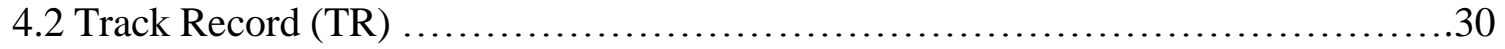

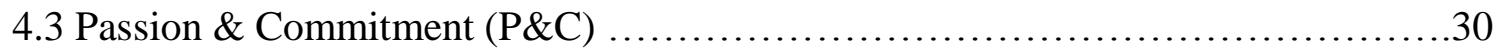

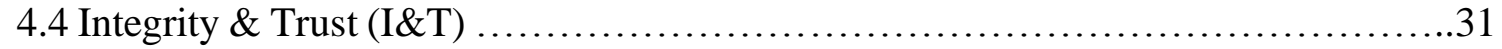

4.5 Technology Knowledge (TK) ............................................. 32

Chapter 5. Research Methodology .........................................................

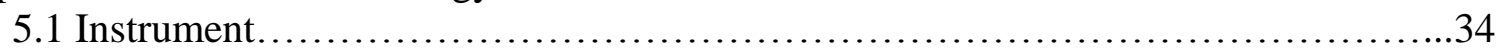

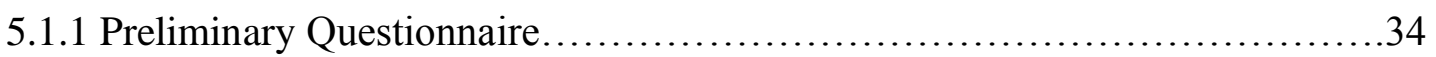

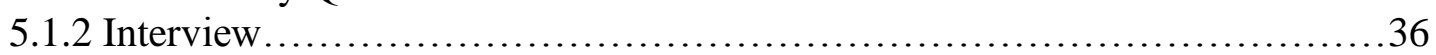

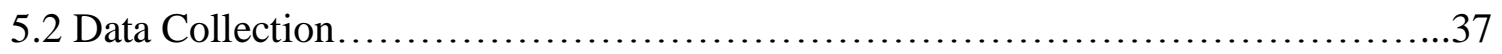

5.3 Sample Demographic.................................................. 38

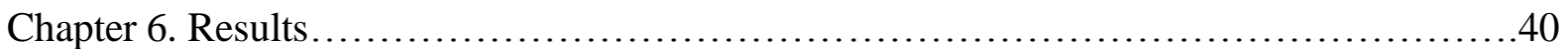

6.1 Questionnaire............................................................ 40

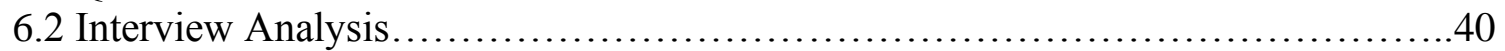

6.2.1 Industry Experience .................................................. 41

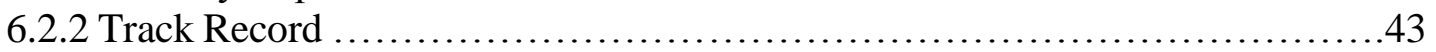

6.2.3 Passion \& Commitment................................................... 45

6.2 .4 Integrity \& Trust...................................................... 47

6.2 .5 Technology Knowledge............................................... 51

6.2.6 Open-mind \& Adaptability ............................................. 51

6.3 Relationship Model........................................................ 53

6.4 Results Summary for Construct Occurrences.................................54 
Chapter 7. Summary of Results and Discussion........................................56

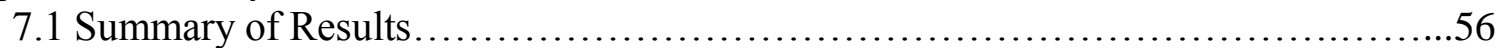

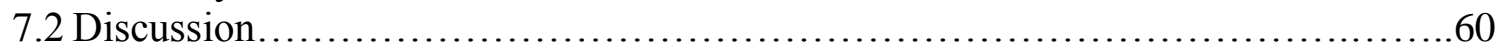

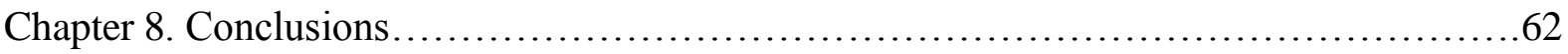

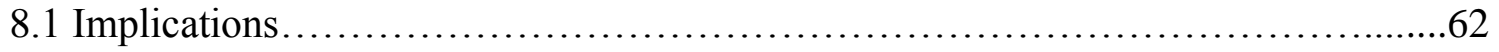

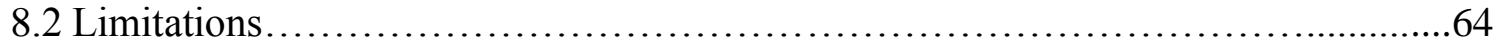

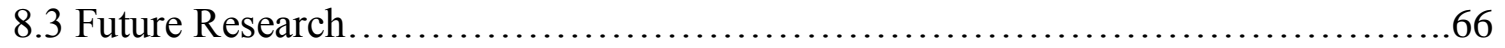

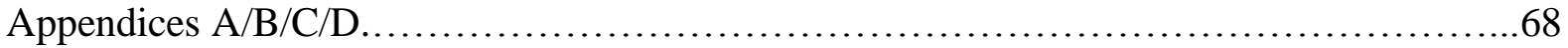

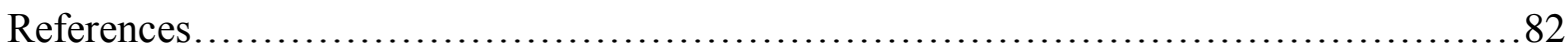




\section{List of Figures}

Figure 2.1 Investment Decision Making Entrepreneur Criteria Model for Angels.............5

Figure 3.1.1 Angel Investors' Startup Financing.....................................

Figure 3.1.2 Due Diligence Checklist...........................................

Figure 3.3.1 Angel's Top Three Industry Sectors for Investment.......................9

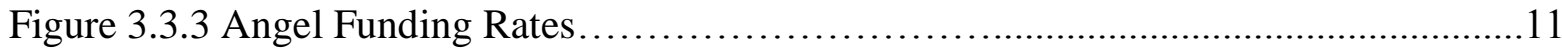

Figure 3.5 Plots of Significant Interactions for Industry Experience.....................18

Figure 4.1 Proposed Research Model...................................................33

Figure 6.3 Relationship Model of Entrepreneur's Qualities and Angel Investing.............53 


\section{List of Tables}

Table 3.5.1 Investment Decision Making Criteria for Angels............................16

Table 3.5.2 Results of Angels' Investment Decision Criteria for Management Team........22

Table 3.5.3 Results of Angels' Investment Decision Criteria for Startups...................23

Table 3.5.4 Angel's Deal Rejection Factors....................................... 25

Table 6.4.1 Total Number of Construct Occurrences....................................54

Table 6.4.2 Total Number of Construct Occurrences in Relation to Immigrant Status

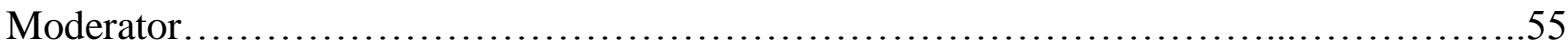

Table 7.1.1 Summary of Findings by Propositions....................................56

Table 7.2.2 Summary of Findings by Moderated Variable by Propositions...................56 


\section{Chapter 1. Introduction}

\section{Start- Up Culture}

With the start-up culture in Canada growing more than ever, start-up activity has become recognized for its significant impact on the entrepreneurial ecosystem (The Economist, 2010). From the establishment of the Start-up Visa to the development of the Accelerator Centre in the Waterloo and Stratford region, innovators have a wide range of access to tailored programing, in-house mentorship, funding, education, and networking opportunities (Bathelt \& Spiegel, 2015). More than 130 start-ups have successfully completed the program at the Centres, and over 1,000 jobs have been created, with total revenue and funding of over $\$ 350$ million (Sim, 2015). The new era of entrepreneurs aims to disrupt industry giants in the areas of technology and science, and among them are many immigrant entrepreneurs who strive to develop their business in Canada (Sim, 2015).

\section{Immigrant Startups}

There are various ways immigrant entrepreneurs can make positive impacts to the economy: they can offer fresh perspective on products and services, sharing knowledge with the community, and revolutionize old and new industries (Stel, Carree, \& Thurik, 2005). In economies where employment rate and opportunities are low for the immigrant population, entrepreneurial ventures could lead to self-employment, rendering start-ups to be self sufficient and vital to economic growth (Stel, 2005). Immigration rates continue to rise especially within the 20 to 44-year-old age group - the population that contributes most to the labour force, capital spending, and taxation revenue (Gignac, 2013). Currently, North American and European policymakers have been looking to outlets such as Social Innovation Funds to encourage social entrepreneurs to tackle society's most intractable problems (The Economist, 2010). Immigrant entrepreneurs have the potential to cause powerful economic and social change through innovative and proactive initiatives. 


\section{Barriers for Immigrants}

However, innovators face multiple barriers to entrepreneurship, such as costly market entry regulations, or unavailable funding opportunities. Furthermore, businesses owned by minority groups may face market-base discrimination that causes even greater difficulty to gain the support necessary to develop their enterprises (Rendall, 2017). In Canada, "the most common challenges faced by immigrant entrepreneurs are language, knowledge of the business culture and practices, and securing financing" (Sim, 2005, p.1). Business inexperience in Canada is another key reason to the financial barrier. Ultimately, the lack of recognition and support for start-ups results in an environment that is difficult for entrepreneurial ventures to succeed and compete with industry giants (Gignac, 2013). Connecting with investors is a crucial skill for entrepreneurs.

\section{Angel Investor vs. Venture Capital}

Venture capital is considered as the formal equity, and Angels as informal equity for funding start-ups. Research shows that currently, the venture capital industry is contracting as well as withdrawing from the early stage investing (NACO, 2016). Angels are a key source of risk capital for the start-up businesses: they are becoming increasingly significant in organizing the market place, and will become a vital source of venture capital for immigrant entrepreneurs (Steier \& Greenwood, 2000). However, research shows that the average Angel investment portfolio does not include immigrant start-ups. With a greater focus on industry research, Angels can explore the economic benefits of investing in immigrant start-ups and diversifying their profiles (Rendall, 2017). Angels who usually have experience developing their own businesses will tend to invest in projects that align their business vision rather than taking greater risks in unfamiliar ventures (Farrell, 2005). Hence, with greater visibility of immigrant entrepreneurs, Angels can conduct further research on their businesses and strategize how these ventures can contribute to the Canadian entrepreneurial ecosystem. Angels must provide 
services that are tailored to meet different needs and individual requirements for immigrants to set up a business, as different immigrant groups face a different set of barriers.

\section{What is covered in this thesis}

In this thesis, I will explore the research questions as well as the goals and motivation of the research. Then, it will introduce the paradigm that forms the overall research design. The literature on Angel investing and immigrant entrepreneurship will be reviewed as well as the Investment Decision Making Criteria for Angels (IDMA). Based on this theory, a series of propositions will be explored to better understand the relationship between Angels and immigrant entrepreneurs. The methodology of the research will be defined, and then results will be presented along with the discussion of the findings. The thesis will conclude with an outline of the future implications, limitations, as well as the potential for future research of the study. 


\section{Chapter 2. Research Questions and Goals}

As the Angels continue to become widely accepted as a means for funding start-ups, it is crucial to monitor and research the relationship between Angels and immigrant entrepreneurship. Specifically, the research asks:

To what extent does the mainstream standard criterion apply to an Angels' decision to engage with immigrant startups?

What are the barriers that the Angel Groups and Immigrant Start-ups face in engaging with each other, and what are the best practices that the two groups might follow to increase engagement?

The review of the literature suggests that Angels tend to stick to a similar pattern when selecting investments for their portfolio, most of which do not include immigrant start-ups. Furthermore, data collection on Angels can be challenging: "the nature of the business is difficult to replicate research studies across domains and jurisdictions and time periods" (Harrison \& Mason, 2008, p.305). As a result, there is very little research being conducted in the area of Angel investment, as it is still a new phenomenon in Canada, making this research topic an important one. I will be using the theory of Investment Decision Making for Angels to predict the characteristics of an entrepreneur that affects the funding outcome, and how an immigrant entrepreneur's status affects this relationship (Maxwell, 2014). This will allow greater identification of opportunity scanning in which the sources of business ideas are identified or created, and how immigrant ventures can become a reality. This framework addresses the importance of investigating beyond what the startups have to offer to Angels, but more so the reasons for Angels to be drawn to particular ventures and the qualities they consciously or subconsciously look for in an entrepreneur (Maxwell, 2014). 
The research builds on previous research conducted on the impact of immigrant startups, and expands to literature on the investment decision making criteria for Angels illustrated in Figure 2.1 (Maxwell, 2014). I will explore the possible link between Angel and immigrant entrepreneurs that could overcome the current decline in the venture capital industry as well as maximizing the impact on Canada's economic and societal growth through immigrant entrepreneurship. In particular, I will examine the current profiles of Angel Groups in Canada and explore their intentions, impact, operations, and strategic partners in the local community to illustrate how they can strategize their business to include immigrant start-ups, a new profitable market. Furthermore, in the light of current events on immigration in the U.S., positive economical and social impacts of migrant bodies will be a relevant topic of research. The research will contribute to both the Angel and Immigrant startups' impact on the entrepreneurial ecosystem in Canada.

\section{Figure 2.1 Investment Decision Making Entrepreneur Criteria Model for Angels}

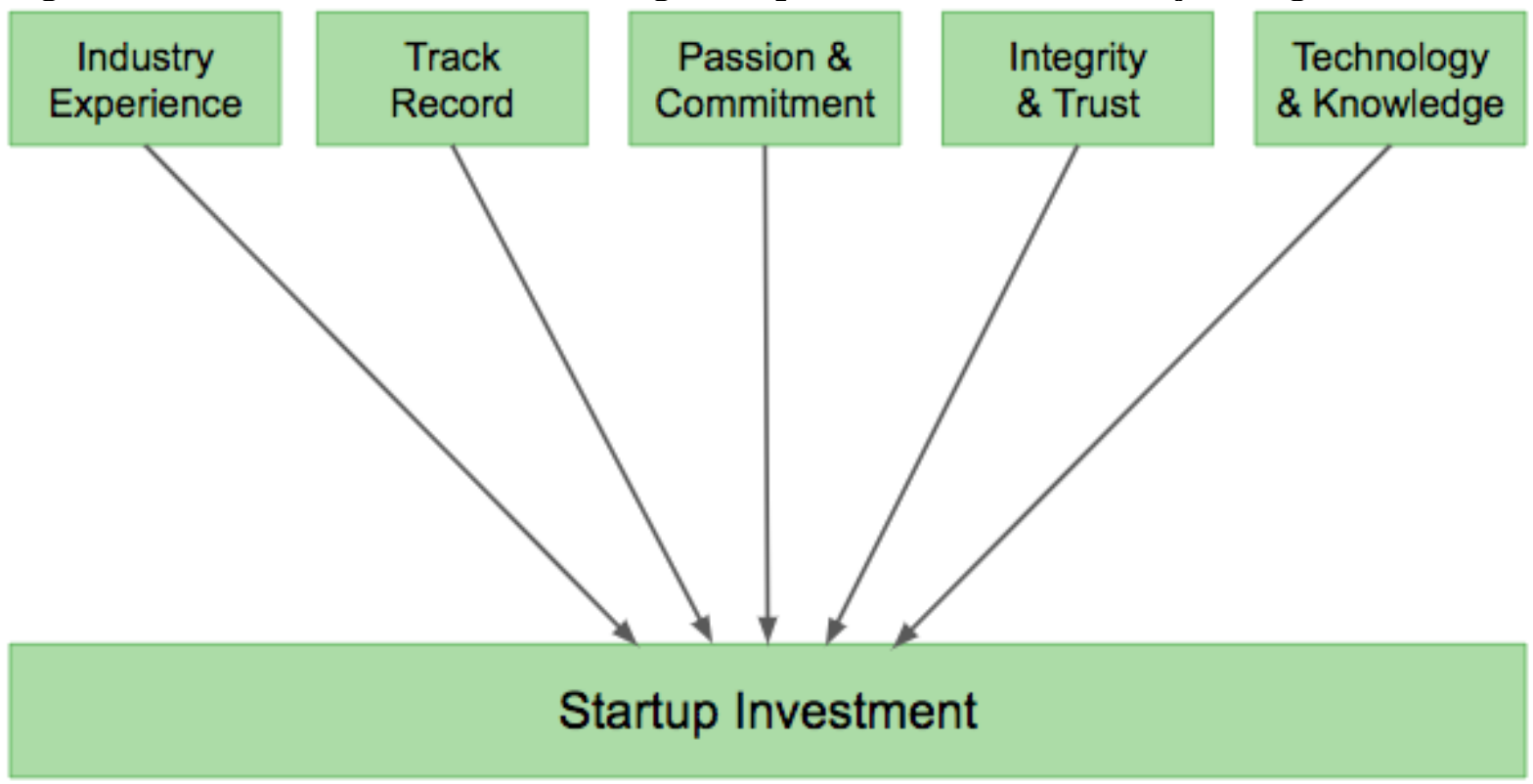

Modeled after Maxwell, A. L., \& Lévesque, M's theory on Business Angel's Investment Decision Making Criteria in "Business angel early stage decision making. Journal" (2014) 


\section{Chapter 3. Literature Review}

\subsection{Startup Financing}

Receiving funding is an integral part to a success of a venture. While many go to family and friends as an initial financing option (Chatham, 2013), entrepreneurs look to mainstream investors for long term financing. With Angels, the three main phases for the funding process are screening, due diligence, and negotiation. In the screening phase, Angels will review a list of startup opportunities to invest in and narrow down their options (Sudek, 2007). Once the Angel has decided which investment opportunities are worth pursuing, they will conduct a further in-depth review of the following: "business plan, marketing plan, sales plan, product details, financials, intellectual property (if any), and any other facets of the opportunity" (Sudek, 2007, p.4). After the due-diligence, Angels negotiate the terms of the deals with entrepreneurs they want to engage with. The two parties will come to an agreement on the investment amount and the share of the company the Angel's investment will represent (WeiDong \& Wei, 2018). The figure below illustrates the overall timeline and milestones of Angels and startups, and the second to fourth step highlighted in blue represents the investment portion of the process.

\section{Figure 3.1.1 Angel Investors' Startup Financing}

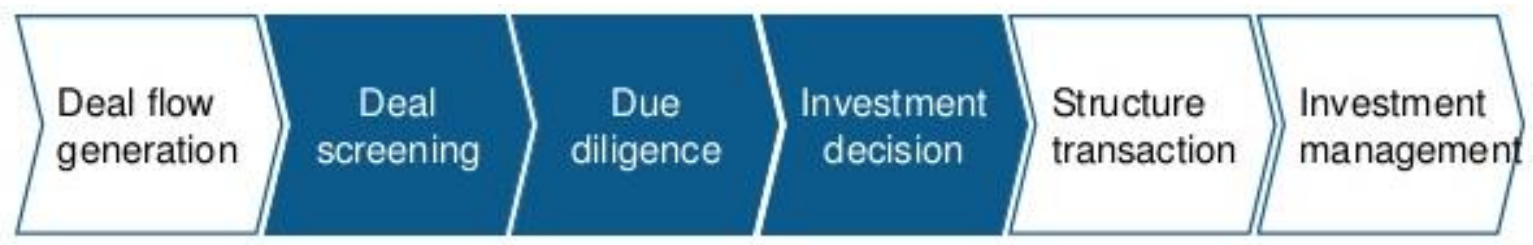

Source: "Evaluation and Due Diligence of Business Angels Investments" by Claude Florin, 2013, A3 Angels 2 CTI Commission for Technology and Innovation, slide 63. Copyright 2013 by Venture Concept.

An Angel's funding process differs greatly to those of friends and family members. Often times, individuals in an entrepreneur's internal circle will forgo the due diligence phase 
as they already have an established relationship with the entrepreneur. Furthermore, they are not as focused on the return on investments in comparison to mainstream investors; Their goal is to support their friend or family member (Van Osnabrugge \& Robinson, 2000). However, literature shows that friends are more willing to be involved in the venture and provide support to the entrepreneur with greater expectations of investment returns than parents of the entrepreneur (Van Osnabrugge et al., 2000). Regardless, for any investor, the first stage of financing is the smallest yet the riskiest. Once entrepreneurs have received funding from their internal circle, they look to Angels who can provide larger funding in the next rounds (Sudek, 2007). The due diligence conducted by Angels are represented in the figure below.

Figure 3.1.2 Due Diligence Checklist

\begin{tabular}{|l|}
\hline Track record of the management \\
\hline Size and growth potential of the market \\
\hline Demand for product/service among target customers \\
\hline Ability to deliver product/service on time and at agreed price \\
\hline Competitive advantage of the product \\
\hline Competitors \\
\hline Marketing and distribution plans \\
\hline Soundness of financial projections \\
\hline Assessment of the intellectual property rights, if any \\
\hline Existing or possible legal contingencies \\
\hline Valuation for the venture \\
\hline
\end{tabular}

Source: "Evaluation and Due Diligence of Business Angels Investments" by Claude Florin, 2013, A3 Angels 2 CTI Commission for Technology and Innovation, slide 75. Copyright 2013 by Venture Concept.

\subsection{Who are Angel Investors?}

Angel Investors are considered to be one of the most "appealing actors in the ecosystem for entrepreneurial businesses" (Bonino, 2018, 592). However, there is limited research on this group in comparison to venture capitalists. Their identifies often remain a mystery. Who are 
Angels and why are they considered a vital player of the startup business? The literature illustrates Angels to have various backgrounds and experiences, with a unique role in the entrepreneurial ecosystem. Despite their diversity in the Angel profiles, there appears to be a common trend in their decision making process for startup investments.

Angels are individuals who are most often associated with high net worth. They invest their own capital in small companies, and typically assume a portion of the equity stake as well as obtain an active role in portfolio companies (Mason, 2008). They are a critical resource for startups, as they take on the role of filling the funding gap between the demand and supply of early-stage equity capital (Johnson \& Sohl, 2012). On the other hand, venture capitalists are often times organized by a professionally managed firm. Hence, an individual venture capitalist is rare (Ward, 2018). Although their goal to provide capital for a startup in exchange for an equity position is similar to that of Angels, venture capitalists pool their investment funds through resources such as pension funds and large corporations like insurance companies to invest in businesses with high rates of return. With a stronger need for higher return rates, venture capitalists will approach businesses with both high growth potential as well as high risk (Ward, 2018). Due to the fact that Angels most often work individually, the stage of engagement and expectations from the business is different to venture capitalists. An Angels initial investment in a business can range from $\$ 100-300 \mathrm{~K}$, which is considered unprofitable for venture capitalists due to the relatively high costs of the administrative expenditures to monitor early-stage startups (Jeng \& Wells, 2000). However, Spence addresses that with any investment in a business, Angels expect "at least a 10-times return on their investments" (2017). Angels also play a vital role in a startup's early stages by providing industrial knowledge, mentoring, management experience, and access to their personal networks (Landstrom, 1993). With the early-stage support of Angels, startups can achieve a working business model and exposure to formal venture capital (Spence, 2017). Angels are commonly 
former entrepreneurs, and are equally enthusiastic about the adventure of investing as much as profit. However, even with their best efforts, statistics show that $90 \%$ of new businesses will fail which means Angels tend to be most risk-adverse in comparison to venture capitalists.

\subsection{Angel Profiles}

\subsubsection{Start-up Industry}

In recent years, the total number of investments has continued to increase. In 2016, Angels made a total of 418 investments, approximately two-thirds of which were new investments, compared to the 283 total investments in 2015 (NACO, 2016). The main areas of interest for Angels in Canada are in the Information and Communication Technology (ICT), Clean Tech, Diversified, New Media, and Manufacturing industries (NACO, 2016). The distribution of the top three industries is shown in the data graph below (NACO, 2016).

\section{Figure 3.3.1 Angel's Top Three Industry Sectors for Investment}

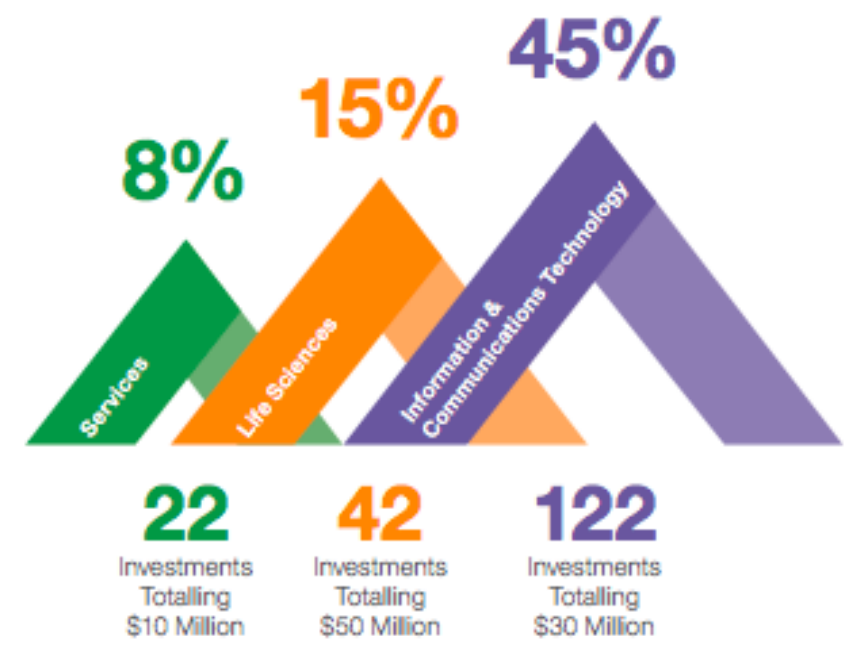

Source: "Report on Angel Investing Activity in Canada: An Analysis of Business Angel Support to the Start-up Funding Continuum" by NACO, 2016, page 2. Copyright 2017 by National Angel Capital Organization.

These industries have been consistently listed as the main areas of interest for Angel investors in literature on Angel profiles. Due to the high rate of investment in these specific industries, it can be assumed that these are the areas in which start-ups provide greater returns for the Angels and are the most successful in the entrepreneurial ecosystem (NACO, 2016). 
There is a lack of depth in explaining why these are the most popular investments: Is ICT the most common form of start-ups for innovators? Are most Angels more knowledgeable in these specific fields and forego opportunities in other industries? Do these industries have the biggest impact on the Canadian economy? And are they the easiest to manage for Angels? The gap in the literature suggests further research is necessary to understand Angel profiles in order to measure how they can further expand their investment profiles. An Angel investor proclaims he has the tendency to seek companies that operate in the technology industry mainly due to the fact that it supports high growth, however, this is not to say that other industries such as business-to-business companies with great industry contacts are not capable of achieving this high level of growth (Spence, 2017). Although a big percentage of investments go towards information and communication technology, Angels are open to different sectors as long as they believe the company has potential to be high-growth drivers.

\subsubsection{Start-up Diversity}

With the high-risk nature of angel portfolios, angel investors should look for greater diversity made in light of existing investments: "As much diversity should be undertaken as is reasonable [as] venture capital portfolios reveal that it is usually a minority for deals that account for most profits" (Van Osnabrugge et al., 2000, p.239). Research shows that within the group of "highly successful entrepreneurs, immigrants will be more successful than nonimmigrants [specifically the immigrant population that are] more likely educated and comfortable with the language and customs of the host country" (Dalziel, 2008, p.27). Although the data does not explain why this is the case, the results suggests the possibility for immigrant entrepreneurs to create more jobs in the host nation to a greater extent than nonimmigrants (Dalziel, 2008). Immigrant entrepreneurs have strong connections within their ethnic circle, and can aid Angels to unleash a new market through investing in immigrant startups. 


\subsubsection{Investment Trends}

Research shows that when it comes to deciding which start-up to invest in, Angel avoid the fully compensatory decision model (Harrison, Mason, \& Smith, 2015). Instead, Angels use a form of shortcut decision-making procedure, also referred to as elimination-by-aspect (Sim, 2005). Due to the vast number of emerging start-ups in the market, the elimination-by-aspect allows Angels to cut down prospects to a more manageable size: if a start-up displays any sign of a drastic flaw, it will be eliminated from consideration in the first stage (Maxwell, Jeffrey, \& Levesque, 2009). Below is an image of the funding rates of Canadian Angel groups in 2016. As demonstrated in NACO's study, only 7.8\% of applications were funded by Angels in 2016.

\section{Figure 3.3.3 Angel Funding Rates}

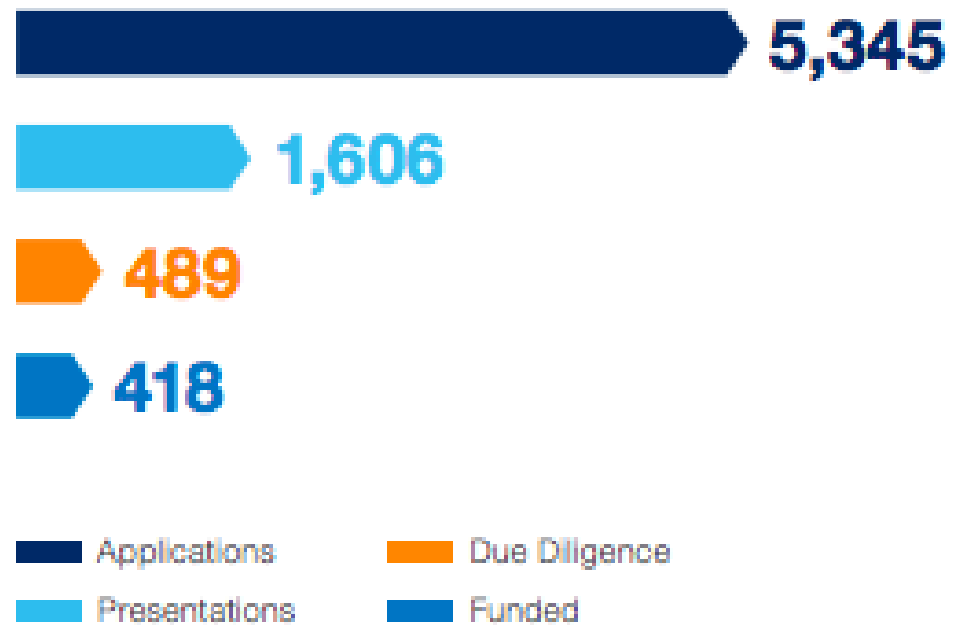

Source: "Report on Angel Investing Activity in Canada: An Analysis of Business Angel Support to the Start-up Funding Continuum" by NACO, 2016, page 1. Copyright 2017 by National Angel Capital Organization.

Carpentier and Surret conducts research on 636 start-up proposals submitted to Angel groups and provides an analysis on the decision making process. In the case of a rejection, it was deducted that the reasons were associated to "market and execution risk; this finding holds for every step of the process for proposals that pass the pre-screen" Carpentier et al., 2015, p.808). Angel tend to apply greater emphasis on market and execution risk over agency risk, and 
“inexperienced entrepreneurs are rejected for market and product reasons" (Carpentier et al., 2015, p.813). Although the types of fatal flaws and specific criteria are not present in the research, the literature provides a useful insight on the behaviours of Angels. The connection between the lacks of immigrant start-ups in their portfolio can be drawn to the Angel's decision to reject any entrepreneurs with very little Canadian business experience. Foreign business is equated to higher risk. It is possible that for management reasons, further research on immigrant start-ups is not conducted as they are eliminated from a potential investment in the first round. Angel Groups can set up a more extensive evaluation process to incorporate immigrant start-ups in their profiles as opposed to eliminating them due to lack of experience. As one of the most important sources of risk capital for entrepreneurial businesses, it is necessary for Angels to consider various types of risks and how they are associated to long term success in order to avoid missed opportunities. A common cause for rejection of funding is due to the lack of an entrepreneur's ability to penetrate a larger market. With a greater vision, and willingness for entrepreneurs to be bolder, investors can provide funding as well as mentoring to further expand their business (Spence, 2017).

\subsection{Angel Investment Operations}

Angels can be categorized as an informal venture capital, operating on risk equity that is fundamental to the start-up development of high potential ventures (Mason, 2006). They are "high net worth individuals who invest in and support start-up companies in their early stages of growth" (Lange, Leleux, Surlemont, 2000, p.41), and work individually or join an established network of Angels. In their research on Angel network affiliation and investment practices, Bonino, Capizzi, Valletta and Zocchi (2018, p.593) make the point that unlike venture capitalists, these networks are not an effort to pool the Angels funding together for investments, but rather, to an organization that focuses on connecting Angels with entrepreneurs. The support they provide businesses can come in the shape of finances as well 
as guidance and assistance with recruiting, management, networks, distribution connections, and beyond, however their main form of funding includes preferred shares, common shares, debentures, and loans (Durufle, 2009). Approximately 94\% of Angels identify as hands-on investors who bring a wide range of experience such as functional expertise, professional experience and industry knowledge to startups (Mason et al., 2002). These forms of funding are adjusted depending on the size, risk, and other factors of a start-up.

They are typically well-educated individuals with high net worth and significant income, and "two-thirds of business angels' principal source of wealth [are] their own past ventures" (Lange, Leleux, \& Surlemont, 2000, p.40). Equipped with a successful history in business development and extensive knowledgeable in the field, they can provide useful connections in addition to funds. Although Angels are a vital source of venture capital, they face difficulty in organizing and managing a supportive network to a diverse range of start-ups (Steier et al., 2000). This is primarily due to the fact that Angel groups have only started to develop in the past few years, and there is a lack of available information on immigrant entrepreneurs. It is evident that Angels have extensive readily available funds, however, the information on operations of connecting with entrepreneurs and accepting or rejecting applications are often omitted in the literature (Whittam, 2010). In addition, Angel groups have only recently gained greater visibility and Angel activity is slowly becoming understood to be a 'professional' activity rather than a 'hobby' (NACO, 2011). However, while some organizations have become recognized as a professional establishment, other groups may still maintain a low profile creating greater difficulty for entrepreneurs to connect with them.

The literature shows that an Angel who seeks their own startups and those who utilize an Angel network have varying outcomes in their investment trends. In Knyphausen-Aufseß and Westphal's research on the value delivery of Angel networks, the results show that Angels do not experience sustainable benefits from their involvement in an Angel network, and may 
even face risks during the investment process: "investment process had a distinctly higher level of insolvency than did those that were financed on the open marketplace" (KnyphausenAufseß, Dodo, \& Westphal, 2018, p168). This may have been caused by the lack of consulting services, which then influenced the implementation of the business plan and the overall success of the business. Nevertheless, the decision making criteria for Angels remain consistent (Maxwell, 2014), and this will be explored in detail to analyze the characteristics of an entrepreneur that lead to an Angel's decision to invest in a startup.

With a greater focus on industry research, Angels can explore the economic benefits of investing in immigrant start-ups and diversifying their profiles. Angels who usually have experience developing their own businesses will tend to invest in projects that align their business vision rather than taking greater risks in unfamiliar ventures (Farrell, 2005). Hence, with greater visibility of immigrant entrepreneurs, Angels can conduct further research on their businesses and strategize how these ventures can contribute to the Canadian entrepreneurial ecosystem.

\subsection{Investment Decision Making Criteria for Angels}

The literature on the investment decision criteria suggest that Angels look at three major components: the entrepreneur, business potential, and products. However, the emphasis lies mostly in the characteristics of the entrepreneur, as Feeney, Haines and Riding notes the majority of early stage investments are focused on the people behind the business over the actual business itself (1999). At the early stages of a business, the stage in which Angels most often choose to engage, it can be difficult to judge its short and long-term success. Hence, the Angels' tendency to judge the capability of an entrepreneur to determine the capability of the business. Haines' research illustrates how heavily Angel's weigh the characteristics of an entrepreneur during the investment decision making process: "I invest in jockeys not horses. Good jockeys will ride good horses...I didn't always feel this way, but there's only one thing 
that makes the world go round and that's who are sitting around this table-people, and if you have people with the wrong expectations, then you are in trouble to start with. If you can get the right kind of people with the right tools that you want to work with, then that can make a whole lot of difference” (p.26, 2003). In Maxwell and Levesque's work on Angels' early stage decision making, the authors emphasize the shortcut decision making heuristic the investors use which they refer to as elimination-by-aspects (2014). With hundreds of investment applications, this shortcut heuristic allows Angels to better manage their investment opportunities.

As illustrated in the table below, Maxwell presents the five criterion to the decision making heuristic: Product, Market, Entrepreneur, Financial, and Investment (2011). Each criterion is determined by various sub criteria. For the purpose of this study, the focus will be on the "Entrepreneur" criteria, as this is the most vital aspect for Angels when deciding to invest in the early stages of a business. Furthermore, by understanding the how the sub criteria of industry experience, track record, passion/commitment, and technology knowledge, further insight on the barriers between Angels and immigrant entrepreneurs can be covered, as well as insight on how to improve this relationship. 
Table 3.5.1 Investment Decision Making Criteria for Angels

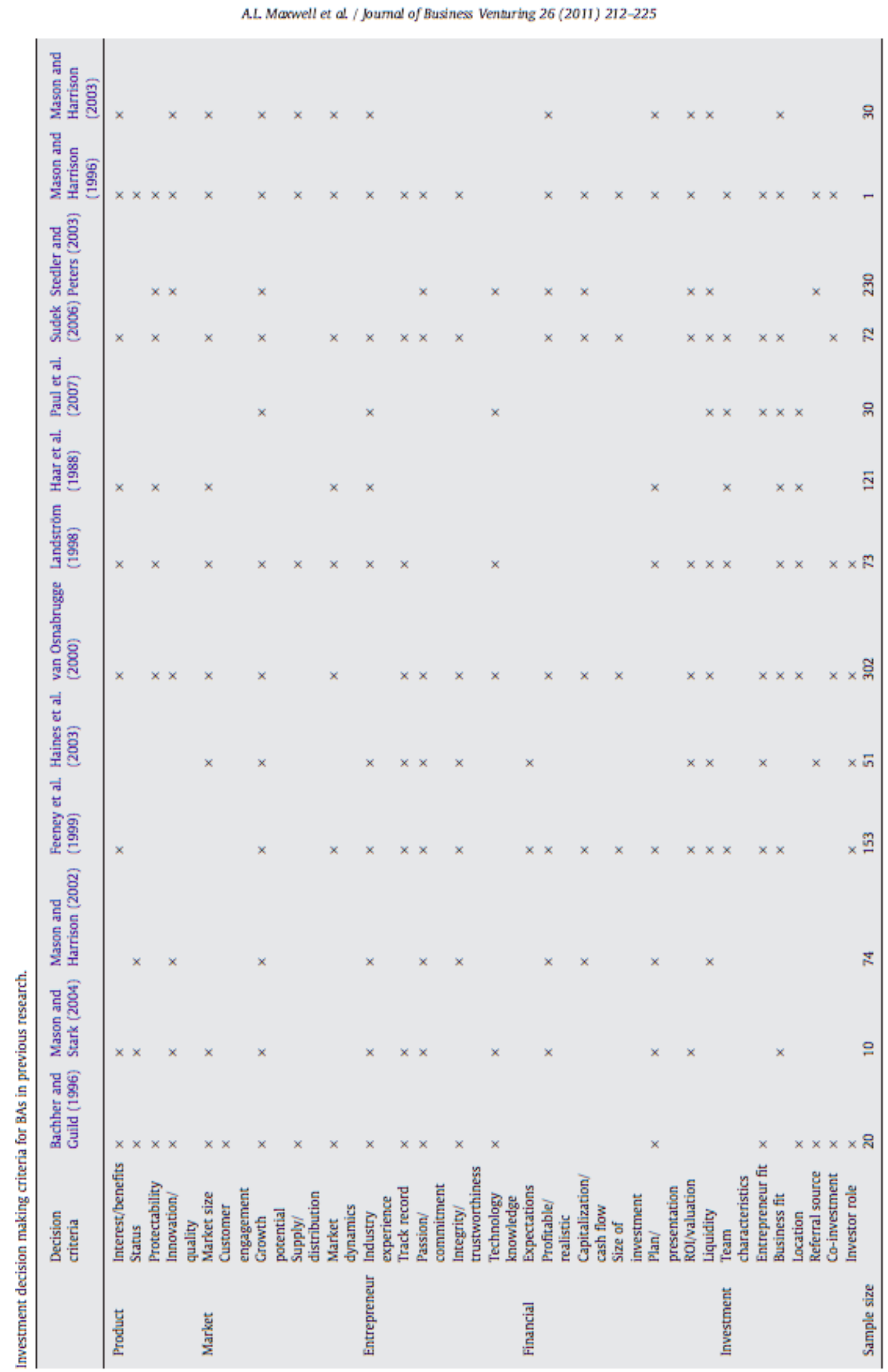

Source: "Business Angel Early Stage Decision Making" by Maxwell, et al., 2009, page 215. Copyright 2015 by Journal of Business Venturing 26 (2011) 212-225. 


\section{Industry Experience}

Angels value startups that operate in an industry in which they have prior experience, or have a high levels of knowledge (Haines, Madill, \& Riding, 2003). This allows them to support the venture beyond the initial investment through mentoring and management, and help grow the business for greater returns from their investment (Mitteness, Baucus \& Sudek, 2012). Angels gain a level of confidence when they are familiar with the business operations, and can provide guidance to entrepreneurs. These industry experiences are categorized into three main types: Operating experience in focal industry, startup experience in focal industry, and investing experience in focal industry (Mitteness et al., 2012). Hence, the individual's knowledge on an opportunity has a significant impact on their perception of the success and feasibility of an opportunity (Krueger, 1993). In Mitchell and Shepherd research on Entrepreneurial Action, "the greater the relatedness of the knowledge underlying the opportunity to that possessed by the individual, the more feasible a potentially valuable opportunity seem" (p.141). When Angels are deciding whether to proceed with the due diligence for a new venture, investing experience increases the relationship between entrepreneur strength and evaluations of funding potential (Kaish \& Gilad, 1991). Over six out of ten investment opportunities are limited due to their lack of knowledge of particular industries, technologies and markets, and as a result, reject an average of $80 \%$ of the investment proposals (Kelly \& Hay, 1996).

In Glaser's study on consensus decision-making, he explains how knowledge extracted from an individuals' experience creates a schemata, and this is used to process information (1984). These schematas allow individuals like Angels to simplify their information processing, making their new venture evaluation process more efficient through combining information they have extracted from previous experiences. Therefore, when evaluating a startup, Angels absorb the information provided to them by the external source, the 
entrepreneur, into their internal source of knowledge, the schemata (Spence \& Brucks, 1997). By combining these two sources of knowledge, the Angel is then able to interpret the situation and make investment decisions on a startup. Delmar and Shane illustrate how the knowledge extracted from industry experience is significant in increasing an Angel's awareness of industry (2006). With industry experience, Angels are more perceptive to the opportunities in the industry, however, prior literature show that different forms of industry experience have a different extent of knowledge extraction and ultimately have a varying impact on the opportunity evaluation process for Angels (Ronstadt, 1988).

"Each different type of experience, [operating, starting a new venture, or investing in a particular industry], lead to different schemata or knowledge structures" (Mitteness et al., 2012). Mitteness' research illustrates that industry operating experience and investing experience have the highest positive impacts on investment criteria and evaluation of funding potential while industry startup experience has the least (2012). Furthermore, each type of experiences affects different stages of the decision making process to varying extents. McMullen and Shepherd even argues that prior experience in an industry can cause Angels to be more critical when evaluating an opportunity (2006). Ultimately, the researchers conclude that the characteristics of an entrepreneur is the greater focus in the decision making process: "Our results regarding industry experience provide further support for the notion that the entrepreneur is the focus when determining whether a deal should proceed to due diligence and the opportunity is the focus when determining whether a deal fits with a particular angel investor" (Mitteness et al., 2012, p259).

\section{Figure 3.5 Plots of Significant Interactions for Industry Experience}

(a) Operating experience and entrepreneur strength (b) investing experience and entrepreneur strength (c) operating experience and opportunity strength (d) startup experience and opportunity strength (e) investing experience and opportunity strength (f) startup experience and entrepreneur strength $(\mathrm{g})$ investing experience and opportunity strength 
a. Operating experience and entrepreneur strength

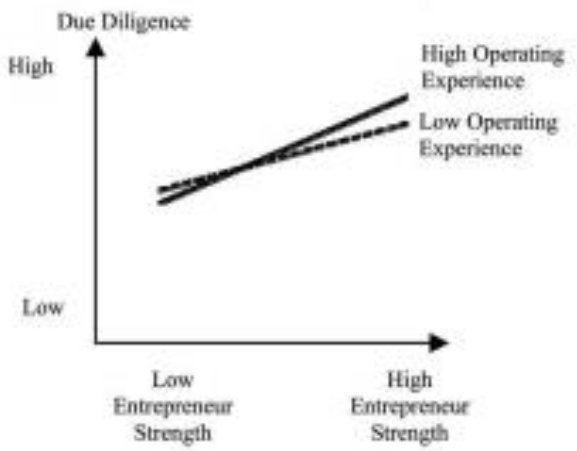

b. Investing experience and entrepreneur strength

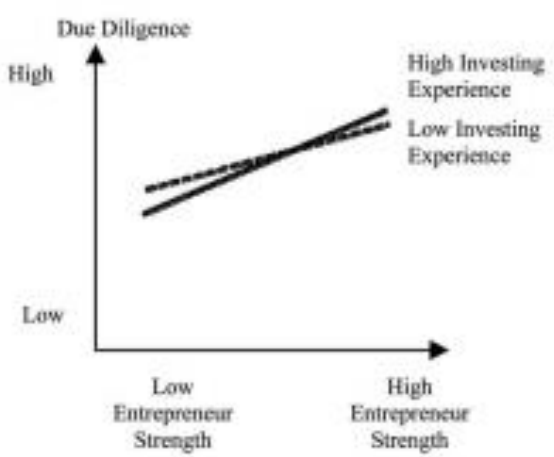

c. Operating experience and opportunity strength

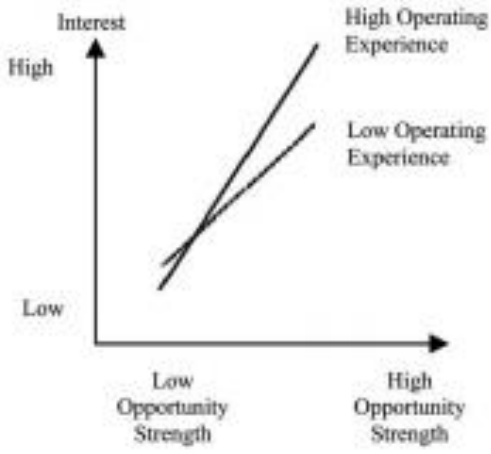

d. Startup experience and opportunity strength

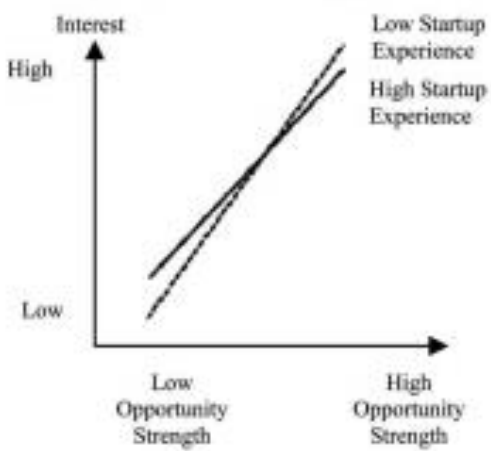

e. Investing experience and opportunity strength

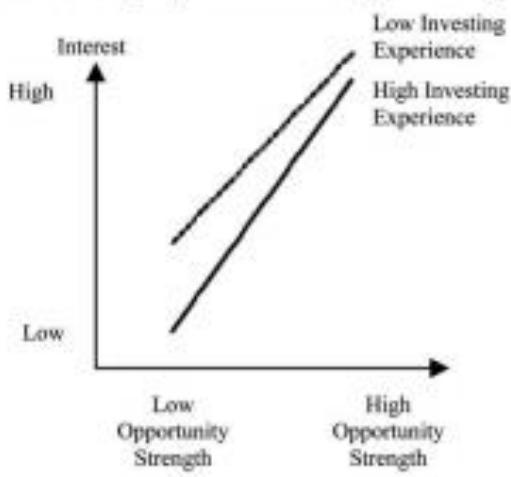

f. Startup experience and entrepreneur strength

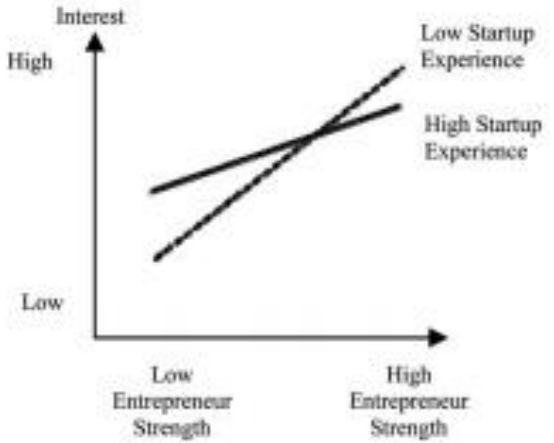

g. Investing experience and opportunity strength

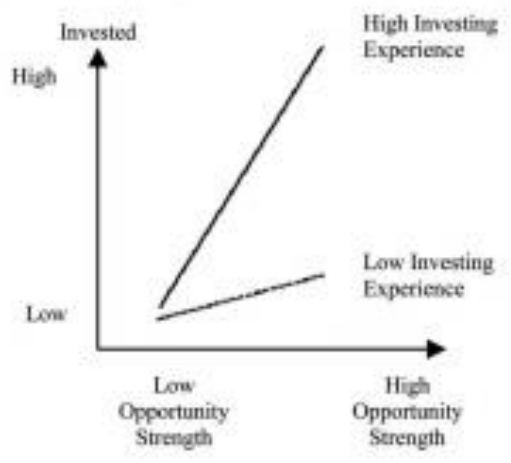

Source: "Horse vs Jockey? How stage of funding process and industry experience affect the evaluation of Angel investors" by Mitteness et al., 2012, page 260. Copyright 2012 by Venture Capital 14(4) (2012) 241-267. 


\section{Track Record}

Another key component to Angels' decision making heuristic is the startup's track record. Feeney et al. conducted an interview with Angels and asked each investor to describe the essential factors that prompted them to invest (1999). A key desirable attribute of an owner, or entrepreneur, was a strong management track record: "Respondents rated prior commercialization experience highly" (p.138). Here are some of the critical attributes investors stressed during the interview in the study: "I recommend investment informs who have proven management and who didn’t promise the sky", "I look for a good track record and proven management", "I would loo for solid track record in principals" (Feeney et al., 1999, p.139).

The literature suggests that a poor track record is the primary reason for rejecting a deal, however, it is not necessary the primary reason for deciding to invest for Angels. Rather, the entrepreneur's ability to realize the potential of their business is a greater criterion amongst other reasons (Feeney et al., 1999). This translates into the entrepreneur's passion and commitment for their business.

Although the decision making criteria remains consistent with most Angels, their process can vary. Following the work of Haines et al., most investors are informal in their due diligence process (2003). Angels will first review financial statements and projections of their potential investment, meet with the entrepreneurs, and conduct informal reference checks to analyze their track records (Haines et al., 2003). Investors will rely on their gut feel during this process to gage whether they can trust the entrepreneurs, which translates into the importance of integrity and trustworthiness criterion of the heuristic (Granovetter, 1985). On the other hand, a small portion of Angels have a greater tendency to take sophisticated approach to their due diligence process. This involves the use of checklists and examining documentations to find evidence about the entrepreneurs seeking investment (Haines, et al., 2003). 


\section{Passion \& Commitment}

A passionate entrepreneur began a prepaid credit card startup with very little experience in financial service and exemplified great enthusiasm by putting up most of his money through mortgaging his house for the business. Despite his lack of experience, his commitment won over his investors (Sudek, 2006). Prior literature emphasizes passion and commitment to be the most important criteria for Angels when looking for successful entrepreneurs (Sudek, 2006). Angels are drawn to the persuasiveness that passionate and committed entrepreneurs exhibit, as they deliver a solid entrepreneurial vision (Benjamin \& Margulis, 2000). Research shows that entrepreneurs who demonstrate the qualities of passion, commitment, and enthusiasm, most often receive greater interest in comparison to those demonstrate a greater business model and product while lacking the passion. In the Angel Investment Criteria, Sudek propose that due to low rate of startup success, Angels perceive entrepreneurs lacking the commitment and enthusiasm will be less likely to succeed; Business success is determined by commitment and passion (2007).

Angels specifically seek entrepreneurs with the passion to "do whatever it takes to work through all of the problems of a start-up to succeed" (Sudek, 2006, p95). In addition to higher confidence in the business success, Angels found passionate entrepreneurs to be more interesting and wanted to build a relationship with such individuals. The importance of passion and commitment goes beyond the entrepreneur, and must be evident in the whole team as well (Benjamin et al., 2000). Sudek's research shows that the passion of the team is the greatest criteria for Angels when analyzing the management team of a startup in the table below. 
Table 3.5.2 Results of Angels' Investment Decision Criteria for Management Team

\begin{tabular}{|l|c|c|c|}
\hline Item & Rank & Mean & STD \\
\hline Passion of the team & 1 & 4.71 & .568 \\
\hline $\begin{array}{l}\text { Perceived sense of survivability of the team (how persistence } \\
\text { they will be without giving up) }\end{array}$ & 2 & 4.42 & .707 \\
\hline Openness of team for mentoring (coachabilty) & 3 & 4.33 & .628 \\
\hline Track record of individual team members & 4 & 4.04 & .759 \\
\hline How complementary the skills of the team are & 5 & 3.87 & .691 \\
\hline Experience of the advisors & 6 & 3.67 & .888 \\
\hline How much experience the team has working together & 7 & 3.22 & .826 \\
\hline
\end{tabular}

Source: "Angel Investment Criteria" by Sudek, 2007, page 99. Copyright 2007 by Journal of Small Business Strategy 17(2) (2007) 89-103.

\section{Integrity \& Trust Worthiness}

Van Osnabrugge et al. assert that integrity and trustworthiness are the top criteria during the funding stage (1998). During each interaction with the entrepreneur, Angels are given the opportunity to build or break down their trust. However, measuring trust and integrity differ for each Angel and is a challenging criteria to quantify. Sudek's suggests that Angels loose trust in entrepreneurs when they avoid questions, or give sly answers without any backing during their interactions. Furthermore, failing to listen to the questions proved to be problematic, and entrepreneurs who provided contradictory answers to Angels' questions lost trust (2006). Regardless of the appeal of the overall business model or product, the majority of Angels lost interest in investing in the case that entrepreneurs provided sly answers. In trust between Entrepreneurs and Angel Investors, Bammes and Colleweart's research showed that a lack of trust resulted in the elimination of growth potential or ROI potential for Angels. An entrepreneur's honesty and trustworthiness was critical in order to attract capital.

Following up on Van Osnabrugge's research with a greater sample size, Sudek's research on Angel Investment Criteria results were similar however, trust-worthiness was the greatest factor for Angels when making an investment decision as shown in the table below. 
Table 3.5.3 Results of Angels' Investment Decision Criteria for Startups

\begin{tabular}{|c|c|c|c|c|}
\hline Investment Criteria & $\begin{array}{c}\text { Rank of Current } \\
\text { Study }\end{array}$ & Mean & STD & $\begin{array}{c}\text { Rank of } \\
\text { Van } \\
\text { Onsabrugge }\end{array}$ \\
\hline Trustworthiness/honesty of the entrepreneur(s) & 1 & 4.81 & 399 & 2 \\
\hline Management Team & 2 & 4.64 & .657 & $\mathrm{~N} / \mathrm{A}$ \\
\hline Enthusiasm/commitment of the entrepreneur(s) & 3 & 4.63 & .592 & 1 \\
\hline Potential exit routes (potential liquidity) & 4 & 4.53 & .712 & 24 \\
\hline Revenue potential & 5 & 4.47 & .581 & 3 \\
\hline Domain expertise of the entrepreneur(s) & 6 & 4.44 & .603 & 4 \\
\hline Growth potential of the market & 7 & 4.29 & .701 & 6 \\
\hline Return on Investment (ROI) & 8 & 4.26 & .805 & 11 \\
\hline Barrier for entry for competitors & 9 & 4.19 & .781 & $\mathrm{~N} / \mathrm{A}$ \\
\hline Product's overall competitive protection (in market segment) & 10 & 4.11 & .815 & 21 \\
\hline Profit margin of the business & 11 & 4.08 & .746 & 15 \\
\hline Track record of the entrepreneur(s) & 12 & 4.00 & .839 & 10 \\
\hline Competition of market segment & 13 & 3.94 & .785 & 17 \\
\hline Liked entrepreneur(s) upon meeting & 14 & 3.90 & .922 & 5 \\
\hline Product's formal competitive protection (patents) & 15 & 3.56 & .933 & 27 \\
\hline Your personal knowledge of the business/industry & 16 & 3.53 & .822 & 27 \\
\hline Ability to maintain low overhead & 17 & 3.46 & 1.020 & 18 \\
\hline Potential of co-investors present & 18 & 3.44 & 1.033 & 18 \\
\hline Advisors currently involved & 19 & 3.40 & .899 & $\mathrm{~N} / \mathrm{A}$ \\
\hline Niche market & 20 & 3.31 & 1.121 & 9 \\
\hline Size of the investment & 21 & 3.26 & .769 & 20 \\
\hline Ability to reach break-even without further funding & 22 & 3.24 & 1.000 & 18 \\
\hline Low initial capital expenditures needed (i.e. on assets) & 23 & 3.22 & .996 & 22 \\
\hline Investor's (your) strengths fill gaps in business & 24 & 2.92 & 1.017 & 20 \\
\hline Ability for involvement possible (contribute skills) & 25 & 2.85 & .914 & 13 \\
\hline
\end{tabular}

Source: “Angel Investment Criteria" by Sudek, 2007, page 98. Copyright 2007 by Journal of Small Business Strategy 17(2) (2007) 89-103. 


\section{Technology Knowledge}

The literature on technology knowledge is lacking. Maxwell's criteria of technology knowledge allude to the domain expertise of the entrepreneur. As illustrated Sudek's research in Table 4.8.3, the importance of the entrepreneur's domain expertise is ranked 6th, which is higher than the entrepreneur's track record or the Angel's industry experience. The entrepreneur's expertise and skills fall under the "human capital" factors, along with their track record and the Angel's industry experience (Haines et al., 2003). However, the literature shows that the personality characteristics of the entrepreneur are greater criterion to the decision making heuristic. This includes: trust worthiness and integrity as well as passion and commitment. These characteristics are strongly connected to the Angel's evaluation of the entrepreneur's work ethic, business understanding, and realistic vision of their venture (Haines et al., 2003).

\section{Investment Rejection Criteria}

As the literature showed the characteristics of the entrepreneur are the more vital when it comes to investment decision making criteria for Angels, the most cited reasons for rejecting an investment was also associated with the entrepreneur's characteristics: " 36 per cent of all mentions and 41 per cent of opportunities were rejected exclusive or in part of this reason" (Mason et al., 1996, p46). The research addresses the people that are deal killers in their interviews with Angel. This is comprised of four main components; The lack of honesty and trustworthiness, lack of knowledge and competence, a lack of realism, and the importance of a personal rapport with the entrepreneur. The Angels expressed the following about their entrepreneurs when they decided to reject an investment opportunity: “A deal killer for me is guys who come in here and ... do not demonstrate a decent understanding of the market or the competition that they're focused on... If I don't have a personal rapport with the individual, it will never get off the ground...I think to myself 'Do I want to be dealing with this guy for the 
next two or three years in an investment?' And irrespective of how good he is I just think I will not do the investment ... That is a potentially very irrational way of looking at things. But it is a deal killer" (Mason et al., 1996, p50).

Table 3.5.4 Angel's Deal Rejection Factors

\begin{tabular}{|c|c|c|c|c|}
\hline & \multicolumn{2}{|c|}{ Mentions } & \multicolumn{2}{|c|}{ Opportunities } \\
\hline & No. & $\%$ & No. & $\%$ \\
\hline $\begin{array}{l}\text { Entrepreneur/Management Team } \\
\text { Gaps in management team/ } \\
\text { management team } \\
\text { not strong enough (11) } \\
\text { One-man show (4) } \\
\text { - Lack of relevant business experience (3) } \\
\text { Entrepreneurs not investing their } \\
\text { own money (1) } \\
\text { Doubts over commitment of } \\
\text { entrepreneurs (1) } \\
\text { No successor to soon-to-retire } \\
\text { managing director (1) } \\
\text { Entrepreneur not willing to listen } \\
\text { to advice (1) }\end{array}$ & 22 & 36.1 & 13 & 40.6 \\
\hline $\begin{array}{l}\text { Finance } \\
\text { - } \quad \text { Financial projections flawed// } \\
\text { unrealistic (7) } \\
\text { - } \quad \text { Not a viable business proposition (3) } \\
\text { - } \quad \text { Seeking capital required (1) } \\
\text { - } \quad \text { Insulficient equity offered (1) } \\
\text { - Potential return not exciting enough (1) } \\
\quad \text { Unable to agree valuation (1) }\end{array}$ & 15 & 24.6 & 11 & 34.4 \\
\hline $\begin{array}{l}\text { Marketing } \\
\text { Marketing strategy flawed/ } \\
\text { incomplete (6) } \\
\text { - Target market not interested in } \\
\text { purchasing product/service (2) } \\
\text { - } \quad \text { Barriers to distribution (2) } \\
\text { Too much/growing competition (2) } \\
\text { - Business has no expansion plans (1) } \\
\text { - Company too small for market (1) } \\
\text { High risk business strategy (1) }\end{array}$ & 15 & 24.6 & 15 & 46.9 \\
\hline $\begin{array}{l}\text { Product } \\
\text { - Technology has been superceded (2) } \\
\quad \text { Product not unique (1) }\end{array}$ & 3 & 4.9 & 3 & 9.4 \\
\hline $\begin{array}{l}\text { Miscellaneous } \\
\text { - } \quad \text { Moncept not thoroughly worked out (1) } \\
\text { - } \quad \text { Dubious business practice (1) } \\
\text { - } \quad \text { Conflict of interest in business strategy (1) } \\
\text { - } \quad \text { Existing shareholders unwilling to sell (1) }\end{array}$ & ) & 9.9 & 6 & 18.7 \\
\hline & 61 & & $32^{*}$ & \\
\hline
\end{tabular}

Note:

"Three of the 35 opportunities were not explicitly rejected by the syndicate: see Table 4.

Source: "Why 'Business Angels' Say No: A Case Study of Opportunities rejected by an Informal Investor Syndicate" by Mason \& Harrison 1996, page 44. Copyright 1996 by International Small Business Journal: Researching Entrepreneurship 14(3) (1996) 271-287. 


\subsection{Immigrant Entrepreneurship}

Immigrants, amongst other visible minorities, experience hardship and faced barriers to pursuing well-paid jobs. Experiences such as this led immigrants in Canada to turn to selfemployment and business pursuits in order to survive (Elie \& Arcand, 2009). As mentioned earlier, the Start-Up Visa Program that was launched in April 2013 has created greater ease for immigrant entrepreneurs to develop their business in Canada. However, applicants must be admitted into a business incubator as well as secure at least $\$ 75,000$ in investments from an angel investor group, or secure $\$ 200,000$ in investments from a venture capital fund (Sim, 2015). This program appears to target highly qualified immigrant entrepreneurs who show promise of creating new jobs and driving economic growth. This group will contrast those immigrants who "enter self-employment as a result of poor job prospects and an inability to otherwise enter the job market" (Sim, 2015, p.10). The limited business knowledge and company's inability to hire skilled employees due to lack of finances are among the challenges immigrant entrepreneurs face in Canada. In the early start-up phase, immigrant entrepreneurs may suffer from a low level of early investment due to bank barriers and being unaware of essential business practices (Neville, Orser, \& Riding, 2014, p.58)

There is inconsistency in the forms of start-ups that immigrant entrepreneurs take up. It is crucial to know if immigrant start-ups align with the industries that Angels commonly invest in such as ICT, life sciences, and services. How the depth of barriers faced by immigrant entrepreneurs presented in the literature is relevant as the issue presents an opportunity for risk equity operating Angel groups (Teixeira, 2001). Furthermore, the value of information on the business decisions of individual groups, and the importance of understanding why certain groups do business differently are important. It shows that Angels must provide services that are tailored to meet different needs and individual requirements for immigrants to set up a business, as different immigrant groups face a different set of barriers. With an approximate 
$11 \%$ of an Angel's portfolio yielding a positive exit, Angels are meticulous with their investment decision and accept less than 1\% of applications (Hudson, 2017). Immigrant entrepreneurs must understand how they can mold themselves and their business to the criterions of an Angel.

Moghaddam's research on high growth entrepreneurial funding argues that culture influences the expectations of decision-makers, and as a result, affects economic outcomes (2014). This is illustrated in instances where investors are more likely to invest in startups that are run with entrepreneurs with the same cultural background. Overall, his research illustrates how an entrepreneurs' characteristics such as personal background can have a significant impact on an investors decision making. Hence, Moghaddam makes the argument that immigrant entrepreneurs rely on different sources of funding in comparison to local entrepreneurs in order to avoid such cultural barriers.

As Chatham demonstrates in his research, entrepreneurs rely heavily on family and friends for to fund their startups (2013). This source of funding is referred to as bootstrapping (Malmström, 2014), and this is especially common with immigrant entrepreneurs. The main reason for this is mainly due to convenience, however, unlike local entrepreneurs who branch off and explore various funding resources such as venture capital and Angel funding, or loans from banks, immigrant entrepreneurs solely depend on bootstrapping to operate their business. Reasons for this were associated primarily with immigrant entrepreneurs' negative experiences with investors and an inability to connect with local Angels. Ultimately, they find comfort in approaching people within their internal circle.

Erdman's research on comparing behaviors across culture's illustrate the extreme difficulty in defining cultural differences and how individuals demonstrate entrepreneurial behaviors (2017). This cultural distance is another reason for immigrant entrepreneurs to approach family and friends over local investors. Kahn, La Mattina, and MacGarvie argues 
immigrant entrepreneurs struggle to communicate their passion and enthusiasm to individual investors (2013). As a result, immigrant entrepreneurs find greater comfort in bootstrapping and approaching individuals in their inner circle who speak the same language or share the same cultural background. Previous literature also highlights the discomfort immigrant entrepreneurs have experienced with venture capitalists mainly due to their inability to communicate their products to locals. Momani has found that in meeting with investors and networking within the community, immigrant entrepreneurs tend to be timid and reserved in comparison to the locals (2014).

Kahn, La Mattina, and MacGarvie explore the reasons for why immigrants are more entrepreneurial than local entrepreneurs (2013). A key factor is the underestimation of an immigrant entrepreneur's skill level (Kahn et al., 2013). This is more common for immigrants who come from non-English-speaking countries, or from a culturally dissimilar country to Canada. More immigrants resort to entrepreneurship in order to financially support themselves as a means to achieve higher pay. The research also suggest immigrants are capable of recognizing opportunities that go unnoticed by local entrepreneurs. 


\section{Chapter 4. Research Propositions}

The research examines how the variables of industry experience, track record, passion \& commitment, integrity \& trust, and technology knowledge effects the variable of angel investing (AI). In this chapter, each construct will be further explored to provide a proposition for the relationship between the constructs and AI, and predict which variable has the highest effect on an Angel's investment decision.

\subsection{Industry Experience (IE)}

When Angels have experience in the industry in which a startup falls under, they are more likely to be invest. Mitteness argues that IE has a positive impact on the relationship between the ideal characteristics of an entrepreneur and the interest at the screening stage as well as the decision to proceed to due diligence (2012). Furthermore, the relationship is "stronger for angels with high industry investing experience versus angels with little experience" (Mitteness, 2012, p.246). In order to successfully pass the screening face, an Angel's experience becomes critical (Kaish et. al, 1991). However, once a startup successfully passes this stage as a result of their common interests and experiences as the Angel, the chances of proceeding to the next faces of funding is increased (Ronstadt, 1988). Mitteness makes the point that during the screening process, Angels specifically look at the entrepreneur's experiences and the industry in which they operate their business (2012). As this seems to be the core criteria during the screening process, the entrepreneur's immigrant status appears to be unrelated to their decision. Therefore, the following proposition will be presented:

P1: There is a positive relationship between industry experience and an Angel's decision making process to invest in a startup.

P1a: The effect of industry experience on an Angel's decision making process is not moderated by the entrepreneur's immigrant status. 


\subsection{Track Record (TR)}

According to Feeney, an entrepreneur's track record is one of the most critical attribute that impacts an Angel's investment decision making process. Proven success brings Angels confidence in engaging with an entrepreneur. On the other hand, the literature also argues that many Angels take an informal approach to the due diligence process, making it difficult to measure how closely they examine an entrepreneur's track record (Haines et al., 2003). However, the literature appears to acknowledge the importance of the track record as it is a quantitative way for Angels to gage the trust worthiness of an entrepreneur, which can then be interpreted to the individual's integrity and trustworthiness (Granovetter, 1985). The level of impact the entrepreneur's track record makes on the decision making process will dependent on how the Angel approaches the screening and due diligence phase. Similarly, to industry experience, if an immigrant entrepreneur can exemplify a successful entrepreneurial track record, their immigrant status should not affect the decision making process. Therefore, the following proposition will be presented:

\section{P2: There is a positive relationship between track record and an Angel's decision making process to invest in a startup.}

P2a: The effect of track record on an Angel's decision making process is not moderated by the entrepreneur's immigrant status.

\subsection{Passion \& Commitment (P\&C)}

The literature demonstrates that passion and commitment is one of the most valuable attributes an entrepreneur can posses in the investment decision making process. According to Angels, an entrepreneur's passion is strongly correlated to business success (Wiltmen, Sudek \& Reed, 2009). Beyond the demonstration of a solid business model and product, there is greater weight on passion and commitment as this quality demonstrates to Angels the 
entrepreneur will do whatever necessary to ensure the success of their startup (Sudek, 2006). The literature does not determine the formality for entrepreneurs to express these qualities, making it difficult to establish what behaviors quantifies as passion and commitment. Such behavioral qualities are not always consistent across cultures. Erdman's research on comparing behaviors across culture's illustrate how cultural differences have had huge consequences on international organizations, and she has demonstrated the extreme difficulty in defining cultural differences and how individuals demonstrate entrepreneurial behaviors (2001). Khan argues immigrant entrepreneurs struggle to communicate their passion and enthusiasm to individual investors (2017). As a result, immigrant entrepreneurs find greater comfort in bootstrapping and approaching individuals in their inner circle who speak the same language or share the same cultural background. Previous literature also highlights the discomfort immigrant entrepreneurs have experienced with venture capitalists mainly due to their inability to communicate their products to local investors. Momani has found that in meeting with investors and networking within the community, immigrant entrepreneurs tend to be timid and reserved in comparison to the locals (2016). Hence, immigrant entrepreneurs may be lacking in demonstrating their passion and commitment to potential investors in comparison to local entrepreneurs. Their actions may not demonstrate that they will do whatever it takes to ensure success of their startup (Sudek, 2006). Therefore, the following proposition will be presented:

P3: There is a positive relationship between passion and commitment and an Angel's decision making process to invest in a startup.

P3a: The effect of passion and commitment on an Angel's decision making process is negatively moderated by the entrepreneur's immigrant status.

\subsection{Integrity \& Trust (I\&T)}

Integrity and trust is another key attribute Angels seek in an entrepreneur when deciding 
to invest in their startup. The literature consistently show that Angels perceive integrity and trust to have a positive impact on a startup's ROI potential (Sudek, 2006). Similarly, to passion and commitment, integrity and trust is hard to measure. Often times, Angels will go with their gut feeling how trustworthy an entrepreneur appears (Van Osnabrugge et al., 1998). It is easier to identify characteristics of an entrepreneur that are untrustworthy rather than trustworthy, for an example, providing contradictory answers to an Angel's question (Sudek, 2006). It is important to note, however, that such an instance may not always be affiliated with the integrity and trustworthiness of an entrepreneur. Immigrants not only have different ways of demonstrating these qualities, but especially for individuals who are new to the country, English will most likely not be their first language (Erdman, 2001). During the processes in which entrepreneurs are asked in detail about their business operations, immigrants may face language barrier in communicating their answers. Furthermore, an immigrant's lack of Canadian work experience could affect their integration into the entrepreneurial ecosystem, working as a potential disadvantage to provide investors with the answers they seek in developing their business. This may hinder their ability to answer Angel's questions to their best ability, especially during a high pressure screening environment. Furthermore, an immigrant's answers may be perceived as contradictory due to the language and cultural barriers. Therefore, the following proposition will be presented:

\section{P4: There is a positive relationship between integrity and trustworthiness and an Angel's decision making process to invest in a startup. \\ P4a: The effect of integrity and trustworthiness on an Angel's decision making process is negatively moderated by the entrepreneur's immigrant status.}

\subsection{Technology Knowledge (TK)}

With $45 \%$ of Angel's industry interest being in Information \& Communications 
Technology, it is no surprise it is expected of entrepreneurs to be well versed in this field. Maxwell suggests that an entrepreneur who is an expert in the field she operates her business is in crucial to attain the interest of an Angel (2014). However, technology knowledge falls under the business capabilities of an entrepreneur along with track record, which the literature argues is not as highly valued as an entrepreneur's personal traits such as passion and trustworthiness. Although the relationship may be positive, it is unlikely to have as positive of an impact as the other criteria. As long as an immigrant entrepreneur can demonstrate their expertise and experiences on paper, their status should not affect the Angel's decision. Therefore, the following proposition will be presented:

P5: There is a positive relationship between technology knowledge and an Angel's decision making process to invest in a startup.

P5a: The effect of technology knowledge on an Angel's decision making process is not moderated by the entrepreneur's immigrant status.

Figure 4.1 Proposed Research Model

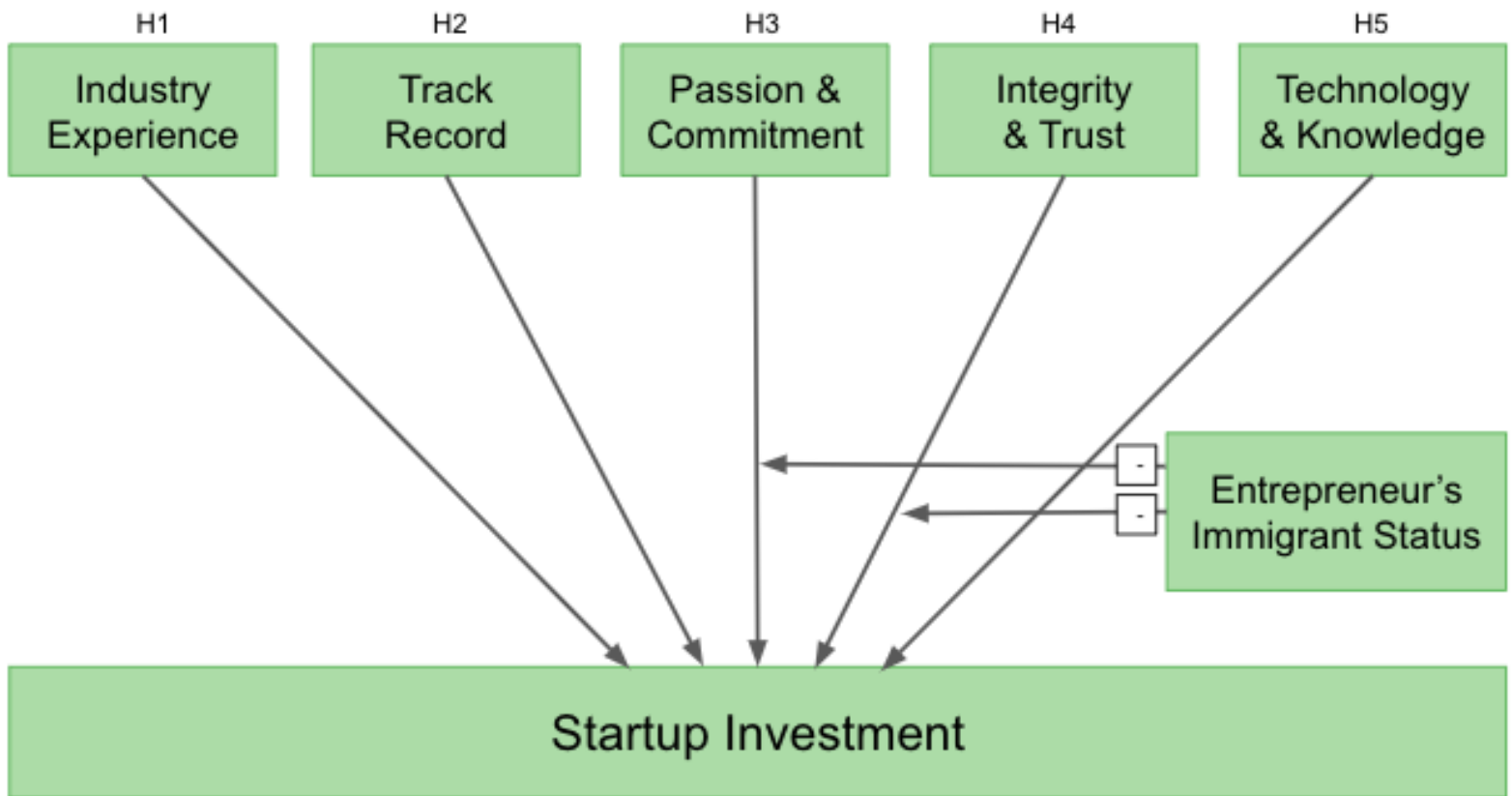

Propositions P1(a) to P5(a) 


\section{Chapter 5. Research Methodology}

This is a mixed method study, with the utilization of an online survey for preliminary research and an interview approach to investigate the relationship between Angels and immigrant entrepreneurs. However, the interviews will be the primary source of study. The survey was used to measure the level of awareness of the two groups in order to identify the current relationship trends. The interview was used to analyze the characteristics of Angels and immigrant entrepreneurs who have successfully engaged with the other group with the aim to determine what factors affect greater engagement levels. With mixed methodology, the research involves the "collection, analysis, and integration of quantitative and qualitative data in a single study" (Hesse-Biber, 2010, p3). Hesse-Biber suggests that mixed methodology approach allows for triangulation, which enriches the findings of the study as well as allowing the researcher to have a better understanding of the research problem (2010). The questionnaire sheds light on the lack of awareness between the Angels and immigrant entrepreneur, which then led to initiating a qualitative methodology in order to provide new insights to existing theories of the investment decision criterion.

\subsection{Instrument}

\subsubsection{Preliminary Questionnaire}

Two online questionnaires were created; One questionnaire was distributed to Angels to measure their level of engagement and awareness of immigrant startups titled "Angel's Engagement with Immigrant Startups", and another was distributed to immigrant entrepreneurs to measure their level of engagement and awareness of Angels titled "Immigrant Startups' Engagement with Individual Investors".

The questionnaire distributed to Angels asked questions to evaluate their experience as an Angel investor: Are you an Angel Investor? How many years of experience do you have as an Angel Investor? How many startups are you currently engaged with? These questions were 
asked in effort to ensure participants are experienced Angels who have a solid understanding of the the investment process and have prior experience with investing in startups. This is then followed with questions regarding their investment patterns: List your top 3 industries you are interested in engaging with. List the top 3 potential risks that could prevent you from investing in a startup. The first question in this section attempts to align the Angel's industry interests to the areas in which immigrants pursue their entrepreneurial ventures. The second question is associated with the investment rejection construct, and examines if the Angel's answers are correlated with an Entrepreneur's characteristics. The last section follows a six-point likert scale from "Extremely Agree" to "Extremely Disagree", and a second variation of "Definitely" to "Definitely not", to measure an Angel's awareness of, and interest in engaging with immigrant startups. It also asks the participant if they identify as an immigrant. This was prompted to analyze the likelihood of an immigrant Angel to invest in an immigrant startup.

In comparison, the questionnaire distributed to immigrant entrepreneurs first determined their immigrant status and their years of experience as an entrepreneur in Canada. Furthermore, the introduction uses the terminology "Individual Investor". As advised by supervisor Dr. Howard Lin, various immigrant startup communities in Canada are unfamiliar with the terminology "Angel" or "Angel Investor". To further clarify an individual investor, the questionnaire describes them to be "a mainstream investor unrelated to [the immigrant entrepreneur], who invests their own personal funds into business opportunities". It is critical to emphasize that individual investors are individuals unrelated to entrepreneurs, as $80-95 \%$ of immigrant startups resort to funds raised by their family and friends, also known as bootstrapping, as their main source of investment in which they rely on (Moghaddam \& Kaveh, 2017). The second section of the questionnaire measures their current level of engagement with Angels, and asks which industry or industries their startup falls under. The third section uses a six-point likert scale from "Definitely" to "Definitely not", and a second variation of 
"Extremely Agree" to "Extremely Disagree" to analyze their awareness of, and interest in engaging with Angels. It also asks participants different factors that have prevented them from reaching out to Angels in the past. They are given the option to choose more than one answer.

Both of these questionnaires requested the consent to participate and participants were given the option to exit the questionnaire at any time. Answering the questions were optional, and both questionnaires included demographic questions related to age and gender.

\subsubsection{Interview}

The questionnaire emphasized the lack of engagement between Angels and immigrant startups in Canada's entrepreneurial ecosystem, however, it also depicted the interest of each group to engage with one another. This led to the business case approach in adopting a qualitative methodology to further understand the necessary factors to create a successful relationship between these two groups. Interviews were conducted with six participants total, three of which were Angels and the other three being immigrant entrepreneurs. The individuals selected for the interview were either a) an Angel who has prior experience investing in immigrant startups, and b) an immigrant entrepreneur who has had funding from an Angel in the past. The goal of the interview was to illustrate various scenarios in which these two groups were able to successfully engage with each other in the past, and analyze how Angels and immigrant entrepreneurs can enhance their level of engagement by replicating these success stories I the entrepreneurial ecosystem. The questionnaire was a discretionary matter in the overall qualitative research interview.

Maxwell's investment decision making criteria is the foundation of the analysis of the interview procedure. The interview focuses solely on the entrepreneur's characteristics that influence the decision making process for Angels, which includes five constructs: Industry experience, passion and commitment, integrity and trustworthiness, and technology knowledge (Maxwell, 2014). The Angels were asked general questions in order to analyze the which of 
the five investment decision making constructs influence the investment decision making process the most. This was done by a construction of prompts which was designed to give structure to the interviews. As McCracken argues in The Long Interview, it is critical that the "investigator allow the respondent to tell his or her own story in his or her own terms" (p.24, 1988) while exercising control over a series of prompts. The interview procedure created an atmosphere of face-safety for participants to share their experiences. The opening questions were simple and informational, such as "How many years of experience do you have as an Angel investor?" and "How many startups have you invested in in the past?". Once these preliminary questions are complete, the interview proceeds to the floating and planned prompts which asks Angels what they look for in an entrepreneur, and the key factors that have resulted in a successful relationship with a startup. This is followed by asking them to share their experience with investing in immigrant startups, and how their relationships with immigrant entrepreneurs compare to non-immigrant entrepreneurs. These prompts were as follows: What are the key factors that you look for in an entrepreneur when deciding to invest? What are the key qualities of the immigrant entrepreneur that you are currently engaged with that creates a successful relationship? How does this compare to your engagement with local investors?". Similarly, the interview procedure is conducted with immigrant entrepreneurs, however, the questions asked will through the perspective of the entrepreneur: "How man years of experience do you have as an entrepreneur? How many Angels have you received funding from in the past?". As not to take away from the participant's experience, the entrepreneurs are asked to describe their relationship with current or previous Angels, specifically how the connection was made and any challenges or interesting insights in fostering a relationship with Angels.

\subsection{Data Collection}

The data was collected in October of 2018. The two sets of questionnaire were distributed to members in Canada's Angel List and immigrant entrepreneurs in the Ryerson 
University network. The interview participants were recruited through the same community as the questionnaire. The criteria required for the interview portion is that the individual has experience engaging with the other party; Angels were selected for the interview after confirming they have experience investing in immigrant startups, and immigrant entrepreneurs were selected after confirming they have received funding from an Angel in the past. Consent was requested for both the questionnaire as well as the interview prior to participation in the study. The data collection of this research was approved by the REB chair, and participants gave consent after reading through the consent form (Appendix A - C). Only once they had clicked "Agree to participate", were they able to move forward with their participation. Individuals who did not click agree were removed from the survey.

A total of 14 participants completed the Angels engagement with Immigrant Startup survey, as well as 13 participants who completed the Immigrant Startup engagement with Individual Investors. Three Angels as well as three immigrant entrepreneurs were interviewed for the study. The survey and interview were only conducted in English. The survey was distributed to individuals across Canada. All participants of the interview are from the province of Ontario.

\subsection{Sample Demographic}

Three Angels and three immigrant entrepreneurs were selected for an interview that lasted on average approximately 30 minutes, consisting of four to five prompts, depending on the overall flow of the interview. For the majority of the time, the participants were given the time to share their experiences; An Angel speaking on their experience with an immigrant entrepreneur, and vice versa. The Angel participants in this case study included a) male with

three startup investments, b) female with ten startup investments, and c) male with 15 startup investments. Amongst the immigrant entrepreneurs, the demographics of the participants 
included a a) male from Africa with two startups, b) female from Asian with one startup, c) female from the Middle East with two startups. 


\section{Chapter 6. Results}

The purpose of the study was to explore an Angel's investing patterns, and examine if an entrepreneur's immigrant status affected these patterns.

\subsection{Questionnaire}

The preliminary questionnaire results show that Angels are unaware of the possibility to engage with immigrant entrepreneurs to a strong extent, however, they are interested to engage. The majority of Angels have probably not approached immigrant entrepreneurs in the past, mainly due to the factors of lack of awareness, as well as cultural and language barriers. Participant Angels were more likely than to have a desire for diversifying their portfolio, and the majority were open to engaging with immigrant entrepreneurs if the opportunity were to arise. On the other hand, the majority of immigrant entrepreneurs who participated in the survey were aware of the opportunity to engage with Angels, but the majority have not attempted to approach Angels in the past. Immigrant entrepreneurs responded that regardless of their interest to engage, they have experienced little to no Angels approach them. The main reasons for immigrant entrepreneurs' hesitation to approach Angels are due to the following: cultural barrier, an Angel's lack of experience engaging with immigrant startups, and language barriers. See Appendix D for further survey results.

\subsection{Interview Analysis}

As depicted in the questionnaire results, the immigrant entrepreneurs who have engagement experience with Angels voiced that connecting with this group is rare and challenging. Likewise, Angels are unaware of immigrant entrepreneurial communities and their desire for funding to expand their startups. An immigrant entrepreneur mentions that it took them a while to finally connect and meet with an Angel investor: 
At first, I had no idea who Angels were. Who are they? Where are they? I did not have the slightest clue what to do in order to communicate with this group and it only happened by chance when my team and I were pitching our startup at a tech conference.

When Angels were asked if they seek to invest in entrepreneurs from an immigrant background, all three responded they did not have a preference and this is not a factor that influences their decision making process:

I have never actively searched to invest in an immigrant startup. I do however like to engage with people that are different than me. I am drawn to creative minds that can provide different perspectives to my own. It challenges me and it makes my work a lot more interesting. It would be so boring to constantly work with people that are similar to myself. What is there to learn from that? And that is probably why I have engaged with immigrant entrepreneurs in the past, not specifically because of my interest in their background but rather the unique way of thinking that they have to offer.

All three Angels agreed that above anything else, the characteristics of an entrepreneur is the most important component of making a decision to invest in a startup. No matter how attractive a product or service may sound, the decision to invest ultimately falls on their overall analysis of the entrepreneur.

\subsubsection{Industry Experience}

Angel participants agreed that they have the tendency to gravitate towards startups that operate in an industry in which they have prior experience working in. Out of the three Angels, all of them had invested in startups which operated in an industry they have prior experience 
in. This makes it easier for them to provide the entrepreneur with guidance in addition to financial support.

I definitely feel more confident when investing in a business I have experience in. Engaging with a startup is not just about providing funding in the early stages. I am very involved in the developmental stages and I want to be able to provide advice along the way to ensure the success of the company. Because I am a very hands-on investor, it is very important for me to build relationships with entrepreneurs who are open to my involvement. It is not as easy to do this when I have very little to no knowledge of the industry.

Investing anything from $\$ 25,000$ to $\$ 100,000$ is not an easy decision (Harroch, 2015), and it can be expected that Angels take their time in selecting their businesses. In the process, the business case show that an Angel's industry experience is indeed a factor in increasing the chances of investing in a startup. This is a tool in which all three Angels utilize to connect with their entrepreneurs as well as gain leverage in obtaining greater voice in the business operation. However, a lack of industry experience did not seem to be a deal breaker. One Angel explains that despite his lack of experience in the startup's industry, his own industry experience can be translated into productive advice for their entrepreneurs:

It would be nice to have a deeper knowledge on the industry in which a startup is operating under, but at the end of the day, I look for entrepreneurs who are experts in this field and have the skills to make their own business successful. Fixating on specific industries can be limiting. It is always interesting to explore businesses in areas that are new to me. The immigrant entrepreneur I am currently engaged with has taught me a lot about the food industry. The possibility to learn [something 
new] was definitely something that encouraged me to build a strong relationship with the entrepreneur.

Angels are drawn to innovative ideas, and the interviews show that a lack of industry experience will not hinder them from engaging with these startups. Industry experience is highly important in providing Angels with confidence to guide entrepreneurs, however, the business case shows that ultimately, it is not a necessary factor in the decision making process.

An immigrant entrepreneur reflects on the advice she was provided by her investor who did not have experience in the industry her business operates in:

My Angel investor is very invested in the day to day operations of my business which is great because she has taught me invaluable lessons on the ins-and-outs of Canada's startup community. She always provides advice on her previous experiences although [she was in the health industry and my startup is in tech], she is great at helping me build my network here.

Out of the three immigrant entrepreneurs, two of them engaged with Angels who have industry experience in their business field. However, the main source of advice they receive are primarily focused on helping their business grow through relationship building in the community.

\subsubsection{Track Record}

The screening and due diligence process administered by Angels varied amongst the three participants. The level of detail in which an Angel choose to investigate the background of an entrepreneur is specific to the investor, however, all Angels in the study has asked about their entrepreneur's previous experiences in the initial stages of the decision making process. 
One Angel says he is very diligent when it comes to checking the track record of an entrepreneur before making his decision:

It is important to ensure the startup I am about to invest in is run by an entrepreneur with a solid track record because it allows me to evaluate how successful their business can be. I want to make sure [that they have] performed well in the past and is an expert in the business they are trying to run. Its just like a job interview. You want to make sure they have a sufficient knowledge and experience in getting their business started.

On the other hand, the two other Angels weigh this process more lightly. Although they do ask to learn more about the previous experiences of the entrepreneur, the Angels are more drawn to the vision that the entrepreneur brings to the table. Checking an entrepreneur's track record is seen more as an administrative task to run a background check on the individual as opposed to a criterion that greatly affects their decision making process. One Angel has expressed the following:

Some Angels may be eager to invest in startups where an entrepreneur has launched multiple startups or have been [working in the industry] for many years. I tend to focus more on the individual's creativity. Their vision is what hooks me in. I am looking to be a part of something truly disruptive and an entrepreneur with very little experience is capable of [this]. Over half of the startups I invest in are started by entrepreneurs who had an out of the box idea that they initially had no idea how to approach because they [were not experts] in this area, but they managed to make it a reality. One of the most successful startup I have invested in is run by a 28 -year-old immigrant who has never [started his own] business before or 
even worked in a startup before. He had such a clear vision and he was able to communicate it to many investors [including myself].

Checking the track record of an entrepreneur is indeed part of the investment decision making process, however, the extent to which a candidate who has delivered successful businesses in the past affects the final decision to invest is minimal. It does however provide Angels with context to understand who the entrepreneur is, and how to build a meaningful relationship. An immigrant entrepreneur who has experience launching two startups has shared their experience:

I thought the Angel was going to question me on the details of my previous venture, but they did not seem to care at all. During the screening process, they spent the whole time discussing my business plan for my new startup and after [sending my documents] on my prior experiences, my investor never followed up on why or how my last startup came to an end. They continued to show interest in solidifying my vision for my new business which felt quite refreshing as I got to present myself on a clean slate.

All three immigrant entrepreneurs were required to share their resumes and briefly talk about their previous experiences during the screening, however, their investors showed much greater interest in their current startup and their vision for the future.

\subsubsection{Passion \& Commitment}

When prompted what they look for in an opportunity to invest, all three Angels answered that they seek a passionate entrepreneur who exemplifies their commitment to the success of their venture. A passionate entrepreneur draws the interest of Angels and it gives 
them a sense of optimism and confidence towards the success of the startup. An Angel shares their experience when initially meeting the immigrant entrepreneur they eventually decided to invest in:

[The immigrant entrepreneur] pitched at a startup event, and his passion to communicate to the audience the impact that his business can make in the tech industry peaked my interest. His idea was great, and his team really managed to impress everyone at the event. It really was a commanding pitch. I remember during the network session after the event, a lot of investors and industry professionals were discussing the potential of his idea, but I was a lot more interested in getting to know him [as an individual]. No matter what his idea was, I thought to myself 'if somebody is this passionate about their business, it has to lead to something'. And sure enough it did. Considering how few startups succeed, [this immigrant entrepreneur] was very determined and confident and I knew I had to be a part of it.

Regardless of how attractive an idea or business model might be, ultimately, Angels weigh greater value in an entrepreneur's demonstration for passion and commitment towards their startup. An Angel expressed emphasized the importance of passion and commitment and how this can positively affect a business:

Its hard to describe it. Its just a feeling I get when I meet someone with a specific kind of energy that I can connect with. Currently I invest in one [immigrant startup]. The [immigrant entrepreneur] is extremely committed to every meeting we have. He continues to to be very transparent in the business operations and regularly provides me with updates. This is a very important aspect of sustaining a strong communication as 
well as overall good relationship. This seems to be his overall attitude towards everything that he does. No matter how small or big a task, he always delivers $110 \%$ and his positive energy truly reflects in the ongoing progress his team is making.

The notion of passion and commitment appears to be a crucial aspect of the decision making process for Angels, however, it appears to be a challenging factor to measure. The Angels commonly used terms such as 'feeling' or 'energy' to quantify the level of passion demonstrated by an entrepreneur that draws their attention. This kind of feeling or energy may be displayed very differently from one entrepreneur to another. When determining the level of passion of an entrepreneur, one Angel mentions he seeks an individual who is energetic and open-minded, while another Angel mentions that she looks for an individual who are professional and displays strong ambition when pitching their startup to investors. Although these characteristics are not necessarily contradictory, the characteristics of a passionate and committed entrepreneur appears ambiguous, or rather, open-ended.

\subsubsection{Integrity \& Trust}

Prior research suggests that integrity and trustworthiness of an entrepreneur, similar to passion and commitment, is one of the most important factors that determine whether an Angel decides to invest in a startup. As study shows, the same result was reflected in this case study. Two Angels mentions that the quality of integrity in an entrepreneur is what they look for next after their passion and commitment, whilst the third emphasizes the importance of integrity and trust above all else.

Although I am initially drawn to the display of confidence and passion somebody has towards their product, I apply greater importance to how transparent they are about their business and 
how well they are able to handle challenges. I have had interviews with entrepreneurs who did not give me direct answers when I enquired about previous challenges their startup has faced or questions about their business model and management team. This is an automatic rejection for me. I invest in the people, not the product. If I cannot even trust the people I am investing in, there is no chance that it will lead to a successful relationship let alone a successful company.

Angels look for the combination of integrity and trust, and passion and commitment in an entrepreneur. Although same valued one more over the other, all three agreed that they will not invest if they were lacking one or the other. These characteristics were the most important aspects of the decision making criteria. Throughout the interview, the Angels stressed they value the entrepreneur over the product they are investing in. One Angel describes his investments as a people business. The screening and interview process is a way to measure the potential strength of a relationship as well as compatibility with the entrepreneur.

Trust is the primary building block for any relationship. In a work setting, I expect my partners to be transparent and keep the communication open. Not all businesses succeed. As an investor, I am very aware of that. There will be a lot of challenges along the way especially during the early stages and as long as my startup is able to include me in the process, I want to do everything I can to provide my expertise. If they close off communication, there is really no point in investing my time and money in them.

Relationship building between an Angel and entrepreneur is critical for a successful startup. Demonstrating the qualities of trust and integrity is challenging, especially when given limited time such as during a pitch or an interview. Immigrant entrepreneurs express their struggle to 
communicate their dedication and trustworthiness as they feel their cultural differences can sometimes be a barrier for them to make an initial connection with Canadian Angels.

It took me a while until an Angel approach me with interest in my startup. As an immigrant entrepreneur, my connections are limited in Toronto. Most of my funding comes from friends and family. The only local form of investment I received was from my manager from my previous job. I rely heavily on my internal community as they are the usually the people that understand me best. And to be honest, I feel the most comfortable [engaging with] the people in my community...but in order to really get my startup out there, I needed to go beyond my internal circle. I was lucky enough to have met an investor that shares the same cultural background as myself. He is not an immigrant, but we were able to make an instantaneous connection because I felt more at east and more confident when I was explaining the vision of my business to him. I have not been very successful with other local investors.

Cultural differences affect the perceived level of trust and integrity. This may be a subconscious tendency for Angels, as in their interviews, they did not mention that an individual's immigrant background would hinder their level of trust or integrity. On the other hand, immigrant entrepreneurs expanded on their challenging experiences of building the trust with an investor. An Angel explains how they managed to grow a trusting relationship with their Angel investor: 
The startups I have launched in the past have always been heavily funded by my family and friends in the community... which I have been truly grateful for. This is always the case, not just with immigrant entrepreneurs.... When I first came to Canada I joined the local church community. Church has always been an important aspect of my life. Over the course of about two years, I have become very close to the people at Church and one day, [one of the members] approached me to find out more about the business I was working on. To my surprise, [he] was an investor and was interested to get involved with my project. I know that if it had not been for the two years in church, and building that trust and friendship over time, my chances of engaging with Angels would be very slim. [My investor] got to really know me and take the time to decide that I am someone he trusts. It was a pleasant surprise to build a connection like this through a [social aspect of my life] and I feel lucky for this.

This entrepreneur made a connection with an Angel through mutual belief and community involvement. Their time spent together in Church allowed for the investor to understand how trustworthy the immigrant entrepreneur is, which led him to engage with the entrepreneur. He invested in the entrepreneur, and he knew that regardless of what the product may be, if the entrepreneur was leading it, it will be successful. This immigrant entrepreneur was fortunate to build connections outside of the entrepreneurial ecosystem, yet this is certainly not the most conventional way in which these two parties meet. This research shows that building connections and relationships are key to increasing engagement with local investors. Simultaneously, the interviews demonstrate that immigrant entrepreneurs have a high tendency to build connections with their internal community, where there is an absence of local Angel investors. Getting involved in the local community and cultural immersion appears to be a necessary form of increasing engagement for immigrant entrepreneurs. 


\subsubsection{Technology Knowledge}

The investment decision making criteria assumes technology knowledge to be amongst the key factors that must be demonstrated by an entrepreneur in order to receive funding from an Angel. The interviews with the Angels suggest that this is not necessarily the case. As demonstrated in the interviews, the characteristics of the entrepreneur was weighed heavier than the business knowledge.

I gravitate towards startups that are innovative in the tech field. Personally I find that area to be most exciting and I really look out for people who know how to use the most high-tech applications to reimagine customer service. That being said, my portfolio is pretty diverse. Overall I would say I consistently engage with entrepreneurs who have a passion to innovate. I do believe that you can be equally creative in a non-technology focused space and that is exactly what [my immigrant entrepreneur] is doing. She has a lot of experience in the medical field and her team has a very solid direction for her startup.

The criterion of technology knowledge was mentioned least frequently in the interviews in comparison to the other decision making criterions. Similarly, to industry experience and track record, technology knowledge is a determinant of an entrepreneur's experience. These qualities have proved to be secondary in comparison to an entrepreneur's qualities such as passion, commitment, trust, and integrity. This leads to a new finding through the interviews.

\subsubsection{Open-mind \& Adaptability}

The Angel participants took a hands-on approach to their engagement with startups. In addition to passion, commitment, trust and integrity, investors also looked for an entrepreneur who is open to feedback and direction from their investors. This quality of open-mindedness has not been addressed in previous literature and was a unique finding. One Angel talked at 
length about how their most successful relationships have been with entrepreneurs who were the most flexible to new ideas:

Something that I witness quite often is entrepreneur's who have too strong of a vision. Of course a strong vision is a good thing but I have noticed over the years that some people have developed an attachment to the idea of their end product and is unable to try new things and...take criticism or feedback well. Things never end up the way you've imagined it too and that's okay. If anything, that is better! You change and adapt for the better. I think as an investor this is a pretty big way we can [provide guidance] and coach the entrepreneur. Obviously we don't have all the answers but an entrepreneur's ability to take feedback well and take risks and be open to new ideas is a testament to the future growth of a startup. It was interesting to work with [my immigrant entrepreneur] because she was constantly trying to approach things from a different angle... and was receptive to the advice I have provided her along the journey. Of course at the end of the day she calls the shots, and not everything I had said was implemented into the business but that's okay! Her willingness to push boundaries and recreate her vision was one of the main reasons for why her startup did as well as it did.

An entrepreneur could display immense passion and commitment to their startup, but if too fixated on a path, the Angels claim they could face a dead end. Adaptability is important for a successful startup, as well as a successful entrepreneur. Another Angel commented:

I'm the type who likes to take on a more hands on role as an investor so when I approach startups I always try to gage how receptive they are towards a more involved investor like myself. Like if an entrepreneur is just looking to get financial support to 
get their startup going, that's great but I would probably not engage with them.

Thus, a more hands-on investor requires entrepreneurs to be accepting and open-minded to the advice provided by their Angels. An immigrant entrepreneur shares their story about shifting their business model to address a bigger business problem:

My team utilizes technologies such as augmented reality to disrupt the card and gifting industry. During the process of trying to partner with retailers for our product, we realized a key issue that a lot of retailers face in Canada which is the abundant return of products from customers. So, we decided to start a new venture where we help retailers help their customers to virtually try on and test the sizing of a product in their homes before buying online...It was an unexpected turn of events, but I've learned that being able to pivot and adapt is necessary when you are trying to solve a business problem. I guess now we have a bigger picture of what our product can do and it is very exciting.

This entrepreneur's Angel investor has continued to also invest in the new venture. Demonstrating the ability to shift the business vision has proved make a positive impact on this individual's investor.

\subsection{Relationship Model}

\section{Figure 6.3 Relationship Model of Entrepreneur's Qualities and Angel Investing}

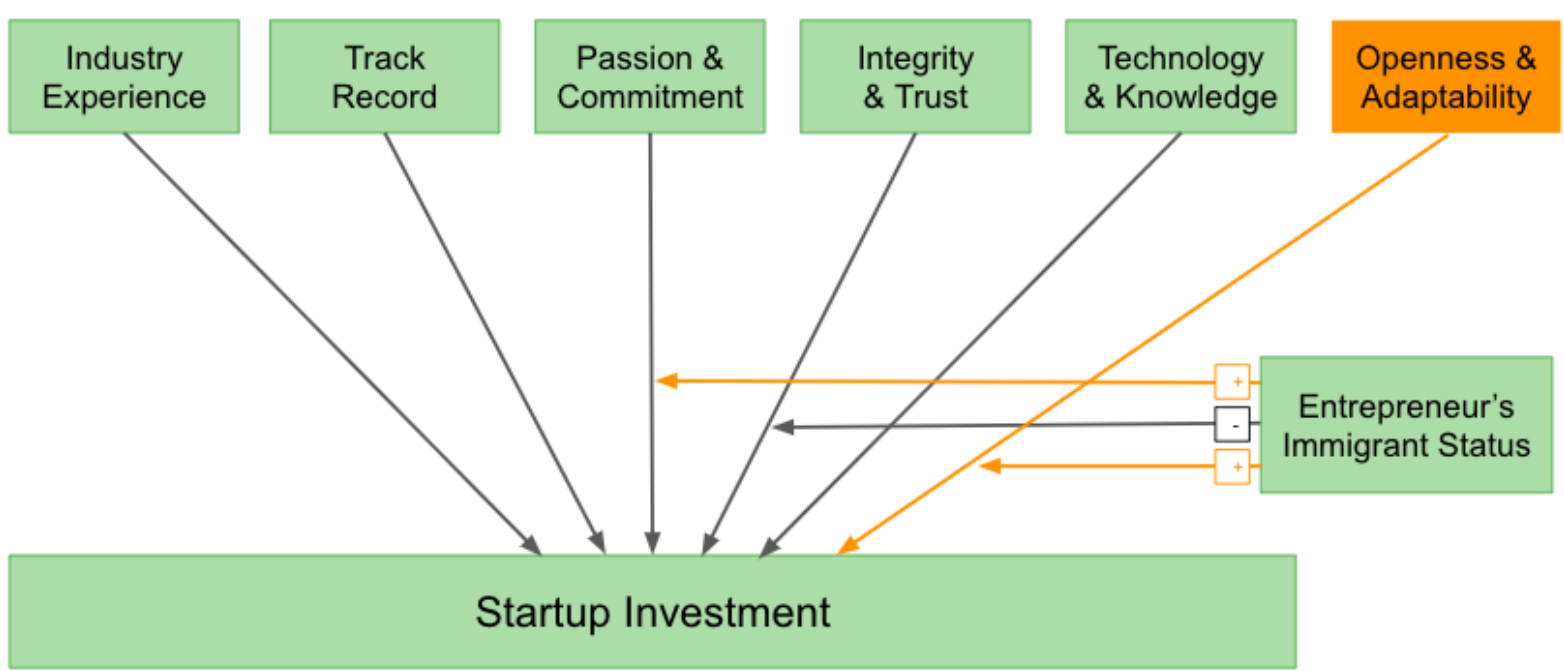


The study showed that the Openness \& Adaptability of an entrepreneur is an integral factor that affects the investment decision making process for Angels. When entrepreneurs demonstrate this quality, Angels are more likely to invest in their startup. This is a new construct that has not been explored in previous literature. Amongst the five constructs from the IDMA, all of the qualities demonstrated by entrepreneurs had a positive relationship towards an Angels investment towards the startup. Within the six total constructs which displayed a positive relationship with startup investment, the relationship between Passion \& Commitment, Integrity \& Trust, and Openness \& Adaptability, with startup investment was moderated by an entrepreneur's immigrant status.

\subsection{Results Summary for Construct Occurrences}

Table 6.4.1 Total number of construct occurrences

\begin{tabular}{|c|c|c|c|c|c|c|}
\cline { 2 - 6 } \multicolumn{1}{c|}{} & $\begin{array}{c}\text { Industry } \\
\text { Experience }\end{array}$ & $\begin{array}{c}\text { Track } \\
\text { Record }\end{array}$ & $\begin{array}{c}\text { Passion \& } \\
\text { Commitment }\end{array}$ & $\begin{array}{c}\text { Integrity \& } \\
\text { Trust }\end{array}$ & $\begin{array}{c}\text { Technology } \\
\text { Knowledge }\end{array}$ & $\begin{array}{c}\text { Openness \& } \\
\text { Adaptability }\end{array}$ \\
\hline Total & 9 & 13 & 25 & 28 & 5 & 14 \\
\hline Percentage & $10 \%$ & $14 \%$ & $27 \%$ & $30 \%$ & $5 \%$ & $15 \%$ \\
\hline $\begin{array}{c}\text { Frequency } \\
\text { Rank }\end{array}$ & 5 & 4 & 2 & 1 & 6 & 3 \\
\hline
\end{tabular}

Integrity $\&$ Trust was mentioned the most at 28 times throughout the interview process. This was the quality that was highly valued amongst the three Angel investors, and a criterion in which immigrant entrepreneurs argue they had been analyzed for the most during their engagement with Angels. Passion \& Commitment was another key quality that affects the investment decision making process, with $27 \%$ of occurrences amongst all the interviews. These two were the most highly mentioned constructs amongst the six mentioned constructs during the study, and were mentioned far more frequently in comparison to the third frequency ranked Openness \& Adaptability at $15 \%$ of frequency percentage. Similarly, Track Record 
produced $14 \%$ of the frequent mentions. Industry Experience and Technology Knowledge were mentioned the least, ranked fifth and sixth accordingly.

Table 6.4.2 Total number of construct occurrences in relation to immigrant status moderator

\begin{tabular}{|c|c|c|c|c|c|c|}
\cline { 2 - 6 } \multicolumn{1}{c|}{} & $\begin{array}{c}\text { Industry } \\
\text { Experience }\end{array}$ & $\begin{array}{c}\text { Track } \\
\text { Record }\end{array}$ & $\begin{array}{c}\text { Passion \& } \\
\text { Commitment }\end{array}$ & $\begin{array}{c}\text { Integrity \& } \\
\text { Trust }\end{array}$ & $\begin{array}{c}\text { Technology } \\
\text { Knowledge }\end{array}$ & $\begin{array}{c}\text { Openness \& } \\
\text { Adaptability }\end{array}$ \\
\hline Total & 0 & 0 & 3 & 4 & 0 & 7 \\
\hline Percentage & $0 \%$ & $0 \%$ & $21 \%$ & $29 \%$ & $0 \%$ & $50 \%$ \\
\hline $\begin{array}{c}\text { Frequency } \\
\text { Rank }\end{array}$ & 6 & 6 & 3 & 2 & 6 & 1 \\
\hline
\end{tabular}

Openness \& Adaptability was impacted the most by the moderator of an entrepreneur's immigrant status, with $50 \%$ of the mentions during the data collection. This was a positive moderator to the relationship. Passion \& Commitment and Integrity \& Trust were also moderated by immigrant status of an entrepreneur to a smaller extent, with an overall negative impact on the relationship to startup investment from Angels. Amongst the other four constructs, there were no evident impacts on the relationship due to an entrepreneur's immigrant status with $0 \%$ of frequency throughout the interviews. 


\section{Chapter 7. Summary of Results and Discussion}

\subsection{Summary of Results}

This researched used the IDMCA for entrepreneurial qualities to determine what factors influence an Angel's decision making process, and how an entrepreneur's immigrant status affects the relationship. A total of six interviews were conducted, with three Angels who have demonstrated a successful investment relationship with one or more immigrant entrepreneurs, and with three immigrant entrepreneurs who have experience engaging with Angel investors in Canada. The results of the interview demonstrate that integrity and trustworthiness is the bigger factor in the investment decision making process, passion and commitment having the second greater impact, the track record having the third greatest impact, industry experience having the fourth greatest, and technology knowledge having the smallest affect (See Table 7.4.1). The table below shows the propositions that were accepted or rejected throughout the case study. As illustrated in the tables below, not all propositions were accepted.

Table 7.1.1 Summary of Findings by Propositions

\begin{tabular}{|c|c|c|c|}
\hline $\begin{array}{c}\text { Research } \\
\text { Propositions }\end{array}$ & $\begin{array}{c}\text { Independent } \\
\text { Variable }\end{array}$ & Dependent Variable & Result \\
\hline P1 & IE & AI & Accepted \\
\hline P2 & TR & AI & Accepted \\
\hline P3 & P\&C & AI & Accepted \\
\hline P4 & I\&T & AI & Accepted \\
\hline P5 & TK & AI & Accepted \\
\hline
\end{tabular}

*AI stands for Angel investing

Table 7.2.2 Summary of Findings by Moderated Variable by Proposition

\begin{tabular}{|c|c|c|c|c|}
\hline $\begin{array}{c}\text { Research } \\
\text { Propositions }\end{array}$ & $\begin{array}{c}\text { Independent } \\
\text { Variable }\end{array}$ & $\begin{array}{c}\text { Dependent } \\
\text { Variable }\end{array}$ & Moderator & Result \\
\hline P1a & IE & AI & IS & Accepted \\
\hline P2a & TR & AI & IS & Accepted \\
\hline P3a & P\&C & AI & IS & Rejected \\
\hline P4a & I\&T & AI & IS & Accepted \\
\hline P5a & TK & AI & IS & Accepted \\
\hline
\end{tabular}

*IS stands for immigrant status 
P1: There is a positive relationship between industry experience and an Angel's decision making process to invest in a startup.

P1a: The effect of industry experience on an Angel's decision making process is not moderated by the entrepreneur's immigrant status.

As hypothesized by Haines et al (2003), Mitteness et al (2012), Krueger (1993), and Kaish et al. (1991), there is a positive relationship between IE and AI. The interviews illustrate that Angels are more attracted to ventures that operate in an industry in which they have prior experience in as it provides them with greater confidence and comfort to support the entrepreneur (Glaser, 1984). The statement can be made that EI positively influences an Angel's decision to invest in a startup. This relationship is unaffected by the moderator of an entrepreneur's immigrant status. Hence, an immigrant entrepreneur does not face barriers to engaging with Angels as a result of the industry in which their business operates in.

P2: There is a positive relationship between track record and an Angel's decision making process to invest in a startup.

P2a: The effect of track record on an Angel's decision making process is not moderated by the entrepreneur's immigrant status.

Feeney et al (1999), Haines et al (2003), Granovetter (1985) study on the influencing factor of track record of an entrepreneur is reflected in this research. Themes related to track record was recorded 13 times throughout the case study. The immigrant entrepreneur participants stressed that with any screening and due diligence process with investors, they will require the entrepreneur to provide documents on their previous experiences. When entrepreneurs can provide a proven management in previous endeavors, Angels perceive the entrepreneur to be more trustworthy and reliable. Hence, the statement can be made that TR positively influences an Angel's decision to invest in a startup. However, the evaluation of an entrepreneur's track record varied greatly from one Angel to the other. Although a greater track 
record increases the chances of receiving funding for entrepreneurs, some Angels may not weigh this as heavily during the screening and due diligence process. For immigrant entrepreneurs, the research suggests that their track record will not be impacted by their status when prompted to share their track record with Angels.

P3: There is a positive relationship between passion and commitment and an Angel's decision making process to invest in a startup.

P3a: The effect of passion and commitment on an Angel's decision making process is negatively moderated by the entrepreneur's immigrant status.

As hypothesized by Sudek (2006) and Benjamin (2000), passion and commitment was a strong driving factor for an Angel during their investment decision making process. As mirrored in the study, Angels equate passion and commitment with an entrepreneur's ability to do whatever it takes to make their venture a success (Sudek, 2006). The internal qualities of an entrepreneur performed highly in the results, with passion and commitment being the second most frequently mentioned theme in the case study. The statement can be made that $\mathrm{P} \& \mathrm{C}$ positively influences an Angel's decision to invest in a startup. However, Proposition 3a was rejected as Angels demonstrated that the immigrant entrepreneur's demonstration for passion and commitment functioned as a positive moderator in the relationship. Investors stressed that the strong will of immigrant entrepreneurs with extensive experience to build a startup in Canada worked favorably towards an investment funding. There are greater risks for immigrant entrepreneurs to succeed abroad in comparison to local entrepreneurs who have a great pool of employment opportunities. Hence, the effect of passion and commitment on an Angel's decision making process is positively moderated by the entrepreneur's immigrant status.

P4: There is a positive relationship between integrity and trustworthiness and an Angel's decision making process to invest in a startup. 
P4a: The effect of integrity and trustworthiness on an Angel's decision making process is negatively moderated by the entrepreneur's immigrant status

The literature suggests Integrity and Trustworthiness to be the greatest investment criteria (Sudek, 2017) (Van Osnabrugge, 1998), and this research study mirrored the same results. During the initial screening phase, Angels tend to rely on their gut feeling to determine the level of integrity and trustworthiness of an entrepreneur in order to build a rapport with their entrepreneur and build a successful relationship. Hence, the statement can be made that I\&T positively influence an Angel's decision to invest in a startup. Although the methodology varies for each Angel, a common pattern is to ask questions about during the first encounter to get as much information about the venture as possible. Immigrant entrepreneurs in the study has voiced their discomfort to share everything about themselves as well as their venture, especially within a restrained time. One immigrant managed to build trust with their investor mainly due to the fact that their investor shared the same cultural background, and the entrepreneur felt instantly at ease upon meeting the Angel. Another immigrant mentioned it took up to two years for his Angel to finally approach him about, and this was mainly due to the fact that they built a rapport through Church, and not a corporate or professional environment. The case study show that Angels are hesitant to trust immigrant entrepreneurs, and as propositioned, the effect of IT on an Angel's decision making process is negatively moderated by the entrepreneur's immigrant status.

P5: There is a positive relationship between technology knowledge and an Angel's decision making process to invest in a startup.

P5a: The effect of technology knowledge on an Angel's decision making process is not moderated by the entrepreneur's immigrant status.

Maxwell (2014), Sudek (2017), and Haines et al. (2003) hypothesize that technology knowledge impacts an Angel's decision making, and as displayed in this study, the results 
were the same. Yet, it is important to note that themes relating to technology knowledge comprised of only $5 \%$ of the case study, most of which overlapped with track record. It was the least significant driving factor of the investment decision making process. An entrepreneur with greater domain experience is attractive to Angels as shown in the results, hence, the statement can be that TK positively influences an Angel's decision to invest in a startup, however this is to a much smaller extent in comparison to other constructs. Furthermore, there appears to be no relationship between the technology knowledge of an entrepreneur and their immigrant status in the investment decision making process.

\subsection{Discussion}

According to the findings of this case study, the overall results utilizing IDMCA as the research model has proved to be strongly aligned with the literature. The majority of the propositions were approved, with integrity \& trustworthiness and passion \& commitment being the strongest predictors of investment decision making. However, openness \& adaptability was the third most frequently mentioned theme in the research, and a construct that was not mentioned in previous literature. Additionally, the construct of technology knowledge proved to be far less significant than the four other constructs of Maxwell's IDCM (2014).

As predicted by Sudek (2007), trustworthiness \& integrity of an entrepreneur proved to be the greatest driver of IDCM, with passion \& commitment amongst the entrepreneurial qualities as the second greatest predictor. However, technology knowledge is ranked third greatest entrepreneurial quality, which is not reflected in this research. Track record and industry experience is ranked accordingly, similar to that of the case study. Technology knowledge was the only construct in which the results proved to be drastically different than the predictions of previous literature. Overall, the predictors were accurate in proposition the results of this qualitative research. 
Openness and adaptability was an unexpected construct that was introduced through the interviews with Angels and immigrant entrepreneurs. All Angel participants took a hands on approach towards their involvement with their startups, and had a high expectation and desire to be involved in the business operations on a regular basis in addition to providing monetary funding. They were passionate individuals who wanted to provide advice on growing businesses and help the entrepreneurs expand their network in the startup industry. The research showed that immigrant entrepreneurs had a less extensive network in Canada's entrepreneurial ecosystem, and was very open-minded towards having a hands on Angel investor. Hence, the statement can be made that 1 ) openness $\&$ adaptability positively influence an Angel's decision to invest in a startup, and 2) the effect of openness \& adaptability on an Angel's decision making process is positively moderated by the entrepreneur's immigrant status. In fact, it had the greatest frequency of mentions during the interviews in terms of the correlation between a construct and immigrant status.

This case study illustrates that in terms of the qualities that Angels look for in an entrepreneur, the only barrier that exists would be when being evaluated for their integrity \& trustworthiness. Angels expect entrepreneurs to be up front and willing to share all details of the successes and challenges of a startup in the early stages of engagement. The immigrant entrepreneurs who participated in the study mentioned a lack of comfort to do so in the early stages, which may have affected their chances of engaging with other Angels in the past. The study shows that building a rapport with an investor is perceived by Angels to be a crucial aspect for building a successful company. The concept of being more open to communication with investors during the screening and due diligence process is applicable to immigrants who want to engage with Angels in the future. Furthermore, the passion \& commitment demonstrated by immigrant entrepreneurs have proved to be successful for the participants in the study. This characteristic can be applied for other immigrant entrepreneurs as well. 


\section{Chapter 8. Conclusions}

\subsection{Implications}

The preliminary questionnaire exemplified the lack of engagement between Angels and immigrant entrepreneurs, mainly due to the lack of awareness and the barriers of culture and language between the two groups. It also showed that there was a high level of interest to engage for both Angels and immigrants. This thesis was designed to observe the investing patterns of Angels and identify any barriers that are present for immigrant entrepreneurs to engage with investors. The research aims to answer the following:

To what extend does industry experience, track record, passion and commitment, integrity and trustworthiness, and technology knowledge impact the Angels' decision to engage with immigrant startups?

What are the barriers that the Angel Groups and Immigrant Start-ups face in engaging with each other, and what are the best practices that the two groups might follow to increase engagement?

The paper examines the relationship between Maxwell's IDMCA criteria, specifically the qualities of an entrepreneur, and the strength of its impact on Angel's investing decisions. Furthermore, it considers the moderating variable of an entrepreneur's immigrant status. The thesis aims to expand on the IDMCA theory and explore how the constructs shift when put in conjunction with the construct of immigrant status. Previous literature has shed light on the importance of fostering immigrant entrepreneurship for the social and economic merit it provides to the host nation, however, it does not identify the barriers immigrants face in assimilating into the entrepreneurial ecosystem. Currently, there is a clear lack of awareness and a missed opportunity for these two groups to engage to bring greater innovation in Canada's startup scene. There is a need for research in this area to understand why there is a strong disconnect between the lack of awareness and interest to engage, and why immigrant 
entrepreneurs are not being considered for greater investment funding from individual investors. Unless the gaps and barriers are identified, the level of engagement between Angels and immigrant entrepreneurs can not be expected to grow in the foreseeable future.

For immigrant entrepreneurs, this research demonstrates that, Angels look for passion \& commitment, integrity \& trustworthiness, openness \& adaptability, track record, industry experience, and domain expertise when deciding to invest in a venture. With qualities such as passion \& commitment, integrity \& trustworthiness, and openness \& adaptability, immigrants must be aware of what exactly the investor is looking for. According to the research, the actions and attitudes of the immigrant entrepreneur to portray these qualities appear to get lost in translation. Immigrant entrepreneurs have the tendency to act professional and reserved during the screening phase, however, Angels desire an entrepreneur who is open and communicative, and willing to share their entrepreneurial journey. Angels work individually and has an allocated amount of time to analyze if they can build a rapport with an entrepreneur. As such, immigrants should utilize this time to pitch their business with passion and transparency.

On the other hand, this thesis can help Angels better understand their investing patterns and explore ways to be more open minded in order to diversify their portfolio. With the large amount of applications, it is necessary for investors to determine a shortcut form of eliminating opportunities with greater risk in order to cut down their prospects to a manageable size (Sim, 2005). However, the Angels perceived risk of immigrant entrepreneurs, whether conscious or subconscious, may be hindering them from engaging with an entrepreneur who they can build a successful rapport with. Furthermore, immigrant entrepreneurs have fewer connections within the entrepreneurial community, and struggle to find funding beyond their internal circle of family and friends. Angels can make effort towards increasing visibility in the entrepreneurial community in order to be more accessible to immigrant entrepreneurs. This can 
be done by greater attendance to startup events and networking opportunities as well as having a greater presence online to connect with potential startups.

\subsection{Limitation}

There are various limitations that must be considered for this thesis. It is important to note that the sample size for this research is limiting, with a total of six interviews. Additionally, the preliminary questionnaire had a total of 27 participants. Due to the difficulty in connecting with Angels with prior experience in engaging with immigrant entrepreneurs, the interview takes a qualitative business case approach to demonstrate the best practices of engagement between Angels and immigrant entrepreneurs. Although immigrant entrepreneurs were more accessible and visible in the entrepreneurial ecosystem, similarly, there were very few who had engaged with Angels in the past. Hence, the objective of the interview is to not only examine the patterns of engagement for Angels and immigrant entrepreneurs, but to study the optimal ways for these two groups to engage with one another.

What has become evident through this research is that with any involvement of human factor, each Angel behaves differently and this is reflected in their approach towards investing in a startup. The best practices to engage demonstrated by Angels in the interviews may not translate for other Angels due to factors such as the participants' willingness to take greater risk, or a higher level of comfort with the immigrant population. There are also other biases that may be in play that prohibit Angels from approaching immigrant entrepreneurs. By focusing primarily on success stories, the research is limited in representing the overall behaviors and patterns of engagement with the immigrant population.

Thirdly, with a smaller sample size, it becomes more challenging to depict the Angel community which includes a full spectrum of different types of investors. This could include wealthy individuals, or investors who are organized into Angel groups. There is a lack of 
literature capturing this heterogeneity, and the outcomes of the research may not be applicable for the various types of Angels within Canada.

Another limitation of this study is the sole focus on the entrepreneurial criteria of the IDMCA theory. Beyond the characteristics displayed by an entrepreneur, there are other factors such as the risks and attractiveness of the product, market, finances, and investments of the overall opportunity. In order to demonstrate a wider breadth of the barriers faced by immigrant entrepreneurs in engaging with Angels, non-entrepreneurial related constructs must be considered in order for immigrants to strategize the best practices to attract investors.

As with any qualitative study, it is challenging to create a non-bias environment during a human observation. Participants were only given thirty minutes to share their past experiences, which may have consequently limited them to expanding further on different constructs or mentioning constructs that have not been studied in previous literature. Furthermore, my presence during the interview may have influenced the participant's behaviors. Participants could have been selective of what experiences to share, adapting to what they believed was what I wanted to hear due to the nature and motives of my research. The desire to please the research conductor can affect the accuracy of the data, causing the interview to be less natural or organic. There are evident challenges in providing prompts throughout the interviews that encourage individual creativity, as opposed to directing the participants towards a certain type of answer or predictable outcome. Furthermore, engaging with immigrant entrepreneurs may pose as a sensitive topic. Participants do not want to be perceived as bias for their lack of desire to engage with minority groups, affecting their answers in the overall results. This may have created limitations in the preliminary surveys, however, the interview participants were individuals who have experience engaging with immigrant entrepreneurs. 
The data collected in this research is highly dependent on the observation of the researcher. The topic of the thesis in itself is a bias, as it reflects the personal interests of the researcher. This has the potential for the researcher's perspective to be included in the data collection, affecting the outcome.

\subsection{Future Research}

Further research should be conducted in this field. The theory of IDMCA was limiting in itself, and the results show that there is potential for numerous other factors of an entrepreneur that can influence the decision making process. Previous literature demonstrates the necessity for immigrant entrepreneurship in Canada, however, more research is necessary to understand the gap in engagement between Angels and immigrant entrepreneurs. Research should be conducted with a greater sample size, with consideration of other constructs within the IDMCA theory as well as different forms of Angel investors.

Future research could also focus more on the social aspect of relationship between local investors and immigrant populations. An in-depth analysis on the behavioral patterns of immigrant entrepreneurs and how they display their entrepreneurial characteristics will be helpful in understanding how to better approach and adapt to their business style. In addition, the current literature on Angel's behavioral patterns are vague and often abstract. Many of factors that drive investments are due to an Angel's gut feeling (Granovetter, 1985). Further research must be conducted to quantify what exactly drives these Angels to invest, and what qualities of an entrepreneur gain an Angel's trust. Some of the constructs presented in the IDMCA theory appear to overlap, for an example, track record and technology knowledge. These two constructs are not always mutually exclusive, making it difficult to collect data on which construct is the greater driver in the decision making process. With further research, the IDMCA can be expanded and the patterns of Angel investing can be better understood. 
Angel investment is a growing field. There is far less research being conducted in this area in comparison to venture capitalism due to the lack of formality and ambiguity in different personality types of Angels. Currently, immigrants do not know who Angels are, and Angels are unaware of the opportunity to engage with immigrant entrepreneurs. However, with a greater focus on studying who Angels are and who immigrant entrepreneurs are, the entrepreneurial ecosystem such as incubators and Angel networks can become a more conductive space that creates greater opportunities for diverse groups to collaborate and innovate the startup industry. 


\section{Appendices}

Appendix A: REB Approval

\section{Research
Ethics Board}

To: Erina Shirai

Ted Rogers School of Management

Re: REB 2018-286: Increasing Engagement: Immigrant Startups and Angel Investors

Date: September 26, 2018

\section{Dear Erina Shirai,}

The review of your protocol REB File REB 2018-286 is now complete. The project has been approved for a one year period. Please note that before proceeding with your project, compliance with other required University approvals/certifications, institutional requirements, or governmental authorizations may be required.

This approval may be extended after one year upon request. Please be advised that if the project is not renewed, approval will expire and no more research involving humans may take place. If this is a funded project, access to research funds may also be affected.

Please note that REB approval policies require that you adhere strictly to the protocol as last reviewed by the REB and that any modifications must be approved by the Board before they can be implemented. Adverse or umexpected events must be reported to the REB as soon as possible with an indication from the Principal Investigator as to how, in the view of the Principal Investigator, these events affect the continuation of the protocol.

Finally, if research subjects are in the care of a health facility, at a school, or other institution or community organization, it is the responsibility of the Principal Investigator to ensure that the ethical guidelines and approvals of those facilities or institutions are obtained and filed with the REB prior to the initiation of any research.

Please quote your REB file number (REB 2018-286) on future correspondence.

Congratulations and best of luck in conducting your research.

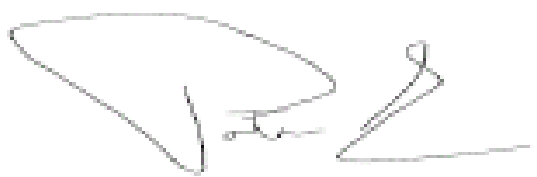

Dr. Patrizia Albanese, $\mathrm{PhD}$

Chair, Ryerson University Research Ethics Board 


\section{RYERSON UNIVERSITY Consent to Participate in Research \\ INCREASING ENGAGEMENT BETWEEN IMMIGRANT STARTUPS AND ANGEL INVESTORS}

\section{INTRODUCTION AND PURPOSE}

My name is Erina Shirai. I am a graudate student at Ryerson University working with my faculty supervisor, Dr. Howard Lin, in the Global Management School at Ted Rogers School of Management. This research is conducted as part of my Thesis, which is an integral part to the completion of my degree. I would like to invite you to take part in my research study, which aims to to examine the current profiles of Angel Groups in Canada and explore their incentives, behaviors, impact, and operations to illustrate how they can strategize their business to include immigrant start-ups, a new profitable market.

\section{WHAT YOU ARE BEING ASKED TO DO}

You are being asked to voluntarily complete this on-line survey. It involves questions about your current investment portfolio and your invest decision making process. It should take about 10 minutes to complete. In order for all of your answers to be collected you must go to the end of the survey and click 'submit survey'. This will demonstrate your full consent to participation.

Selection Criteria: You must be an Angel Investor in Canada to participate in the questionnaire.

\section{POTENTIAL BENEFITS}

There is no direct benefit to you for taking part in this study, however, it is hoped that the research will navigate new ways for Canadian Angel Investors to create diversify and expand their portfolio by collaborating with immigrant entrepreneurs.

\section{WHAT ARE THE POTENTIAL RISKS TO YOU}

Some of the survey questions may make you uncomfortable or upset or you may simply wish not to answer some questions. You are free to decline to answer any questions you do not wish to answer, or stop participating at any time by closing your browser. If you close your browser before getting to the end of the survey and do not confirm your consent to participate at the end of the survey by clicking the 'submit' button your information collected up to that point will not be used.

\section{YOUR IDENTITY WILL BE ANONYMOUS}

The survey is anonymous and as such will not be collecting information that will easily identify you, like your name or other unique identifiers. Although your Internet Protocol (IP) address can be tracked through the survey platform, the researcher/s will not be collecting this information. Your IP address may be observed only to ensure that one individual is not completing the survey multiple times.

\section{HOW YOUR INFORMATION WILL BE PROTECTED AND STORED}

This survey uses Qualtrics which is a United States of American (USA) company. Consequently, USA authorities under the provisions of the USA Freedom Act may access the survey data. If you would rather participate with an email or paper-based survey please contact the researchers. Please note email or paper-based surveys may allow your identity to be known to the researcher/s but if you select this option your information will be kept confidential. 
To further protect your information, data stored by the researcher will be password protected and/or encrypted. Only the researcher/s named in this study will have access to the data as collected. Any future publications will include collective information (i.e., aggregate data). Your individual responses (i.e. raw data) will not be shared with anyone outside of the research team, which consists of the main researcher Erina Shirai and her supervisor Dr. Howard Lin.

\section{YOUR RIGHTS AS A RESEARCH PARTICIPANT}

Participation in research is completely voluntary and you can withdraw your consent at any point up to clicking the submit button at the end of the survey. However, because the survey is anonymous, once you click the submit button at the end of the survey the researchers will not be able to determine which survey answers belong to you so your information cannot be withdrawn after that point.

Any incomplete surveys will be automatically deleted by Qualtrics. If you decide to withdraw or not continue with completing the survey, any data entered up until that point will be deleted.

Please note, that by clicking submit at the end of the study you are providing your consent for participation. By consenting to participate you are not waiving any of your legal rights as a research participant.

\section{DATA STORAGE}

The data will be stored under my Qualtrics account, in which only my supervisor Dr. Howard Lin and myself have access to the results. The data will be stored for 1 year after the approval of the final draft of my thesis for the purpose of verification of results. The data will then be destroyed by deleting the survey from my Qualtrics account.

The data collected will be used in the thesis as part of the research findings section. This can take the a written or graph form, or both. Participants can access an electronic copy of the final results of the study upon request.

\section{QUESTIONS}

If you have any questions about this research, please feel free to contact the researcher/s. Erina Shirai, eshirai@ryerson.ca

Howard Lin, hlin@ryerson.ca

If you have any questions about your rights or treatment as a research participant in this study, please contact the Ryerson University Research Ethics Board at rebchair@ ryerson.ca (416) 9795042.

Please print a copy of this page for your future reference.

START SURVEY https://ryersontrsm.qualtrics.com/ffe/form/SV_6Mwf94bl2ZCRoWx

By clicking SUBMIT I am consenting to participate in this study. 


\section{RYERSON UNIVERSITY Consent to Participate in Research ANGEL INVESTORS}

INCREASING ENGAGEMENT BETWEEN IMMIGRANT STARTUPS AND

\section{INTRODUCTION AND PURPOSE}

My name is Erina Shirai. I am a graudate student at Ryerson University working with my faculty supervisor, Dr. Howard Lin, in the Global Management School at Ted Rogers School of Management. This research is conducted as part of my Thesis, which is an integral part to the completion of my degree. I would like to invite you to take part in my research study, which aims to to examine the current engagement levels between Immigrant Startups and Angel Inestors in Canada and explore how Angel Investors can strategize their business to include immigrant start-ups, a new profitable market.

\section{WHAT YOU ARE BEING ASKED TO DO}

You are being asked to voluntarily complete this on-line survey. It involves questions about your current investment portfolio and your invest decision making process. It should take about 15 minutes to complete. In order for all of your answers to be collected you must go to the end of the survey and click 'submit survey'. This will demonstrate your full consent to participation.

Selection Criteria: You must be an Chinese Immigrant Entrepreneur in Canada (an individual who was born in China and has immigrated to Canada) to participate in the questionnaire.

\section{POTENTIAL BENEFITS}

There is no direct benefit to you for taking part in this study, however, it is hoped that the research will navigate new ways for Canadian Angel Investors to create diversify and expand their portfolio by collaborating with immigrant entrepreneurs.

\section{WHAT ARE THE POTENTIAL RISKS TO YOU}

Some of the survey questions may make you uncomfortable or upset or you may simply wish not to answer some questions. You are free to decline to answer any questions you do not wish to answer, or stop participating at any time by closing your browser. If you close your browser before getting to the end of the survey and do not confirm your consent to participate at the end of the survey by clicking the 'submit' button your information collected up to that point will not be used.

\section{YOUR IDENTITY WILL BE ANONYMOUS}

The survey is anonymous and as such will not be collecting information that will easily identify you, like your name or other unique identifiers. Although your Internet Protocol (IP) address can be tracked through the survey platform, the researcher/s will not be collecting this information. Your IP address may be observed only to ensure that one individual is not completing the survey multiple times.

\section{HOW YOUR INFORMATION WILL BE PROTECTED AND STORED}

This survey uses Qualtrics which is a United States of American (USA) company. Consequently, USA authorities under the provisions of the USA Freedom Act may access the survey data. If you would rather participate with an email or paper-based survey please contact the researchers. Please note email or paper-based surveys may allow your identity to be known to the researcher/s but if you select this option your information will be kept confidential. 
To further protect your information, data stored by the researcher will be password protected and/or encrypted. Only the researcher/s named in this study will have access to the data as collected. Any future publications will include collective information (i.e., aggregate data). Your individual responses (i.e. raw data) will not be shared with anyone outside of the research team, which consists of the main researcher Erina Shirai and her supervisor Dr. Howard Lin.

\section{YOUR RIGHTS AS A RESEARCH PARTICIPANT}

Participation in research is completely voluntary and you can withdraw your consent at any point up to clicking the submit button at the end of the survey. However, because the survey is anonymous, once you click the submit button at the end of the survey the researchers will not be able to determine which survey answers belong to you so your information cannot be withdrawn after that point.

Any incomplete surveys will be automatically deleted by Qualtrics. If you decide to withdraw or not continue with completing the survey, any data entered up until that point will be deleted.

Please note, that by clicking submit at the end of the study you are providing your consent for participation. By consenting to participate you are not waiving any of your legal rights as a research participant.

\section{DATA STORAGE}

The data will be stored under my Qualtrics account, in which only my supervisor Dr. Howard Lin and myself have access to the results. The data will be stored for 1 year after the approval of the final draft of my thesis for the purpose of verification of results. The data will then be destroyed by deleting the survey from my Qualtrics account.

The data collected will be used in the thesis as part of the research findings section. This can take the a written or graph form, or both. Participants can access an electronic copy of the final results of the study upon request.

\section{QUESTIONS}

If you have any questions about this research, please feel free to contact the researcher/s. Erina Shirai, eshirai@ryerson.ca

Howard Lin, hlin@ryerson.ca

If you have any questions about your rights or treatment as a research participant in this study, please contact the Ryerson University Research Ethics Board at rebchair@ ryerson.ca (416) 9795042 .

Please print a copy of this page for your future reference.

START SURVEY https://ryersontrsm.qualtrics.com/ffe/form/SV_6Mwf94bl2ZCRoWx

By clicking SUBMIT I am consenting to participate in this study. 
Appendix D: Questionnaire Results

\section{Angel Investor Confidence in Immigrant Startups}

Q20 - Are you aware of the possibilities to engage with immigrant startups? (Immigrant startup: A _. Page Options

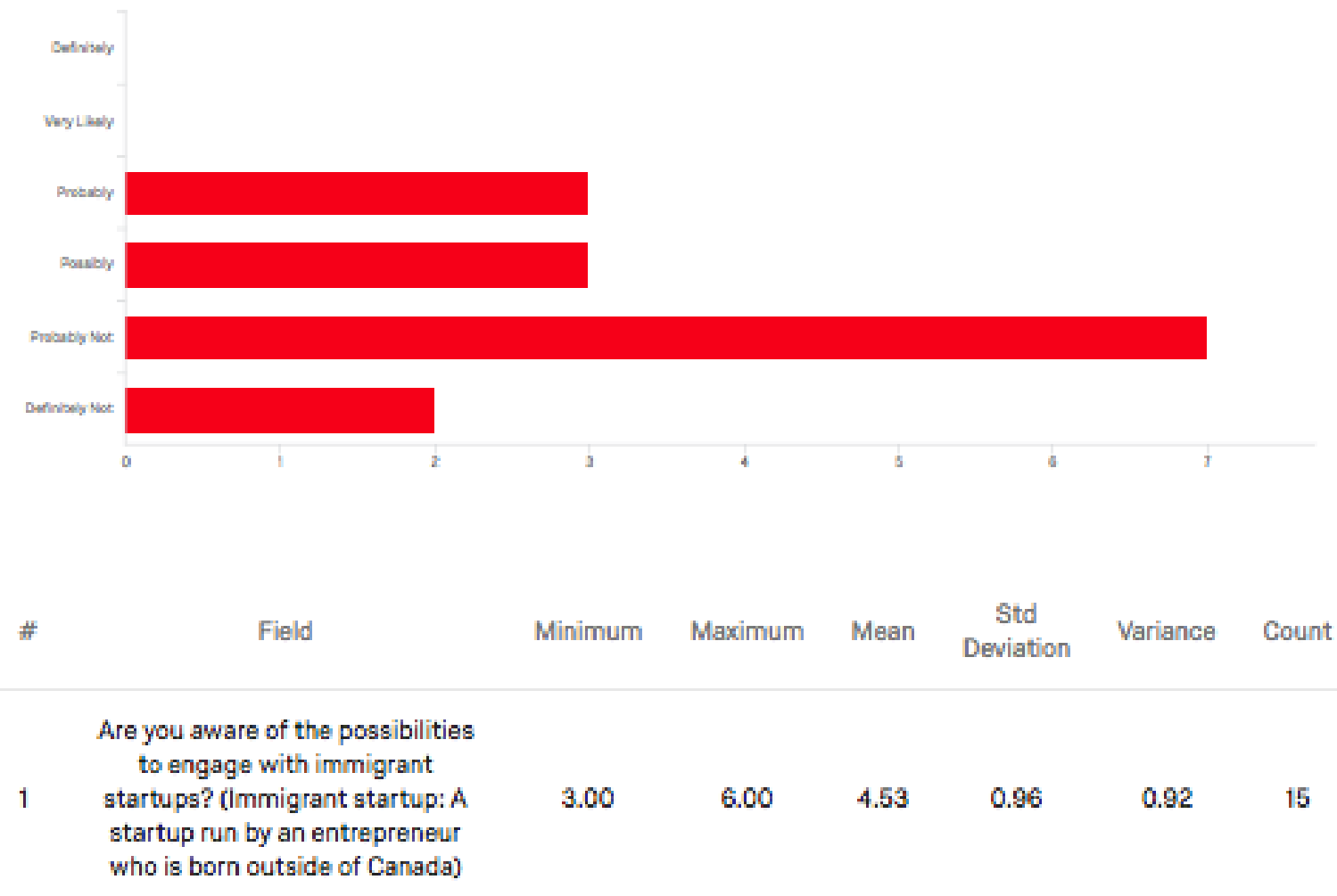

\begin{tabular}{|c|c|c|}
\hline$\#$ & Field & $\begin{array}{l}\text { Choice } \\
\text { Count }\end{array}$ \\
\hline 1 & Definitely & $0.00 \% \quad 0$ \\
\hline 2 & Very Likely & $0.00 \% \quad 0$ \\
\hline 3 & Probably & $20.00 \% 3$ \\
\hline 4 & Possibly & $20.00 \% 3$ \\
\hline 5 & Probably Not & $46.67 \% 7$ \\
\hline 6 & Definitely Not & $13.33 \% 2$ \\
\hline
\end{tabular}




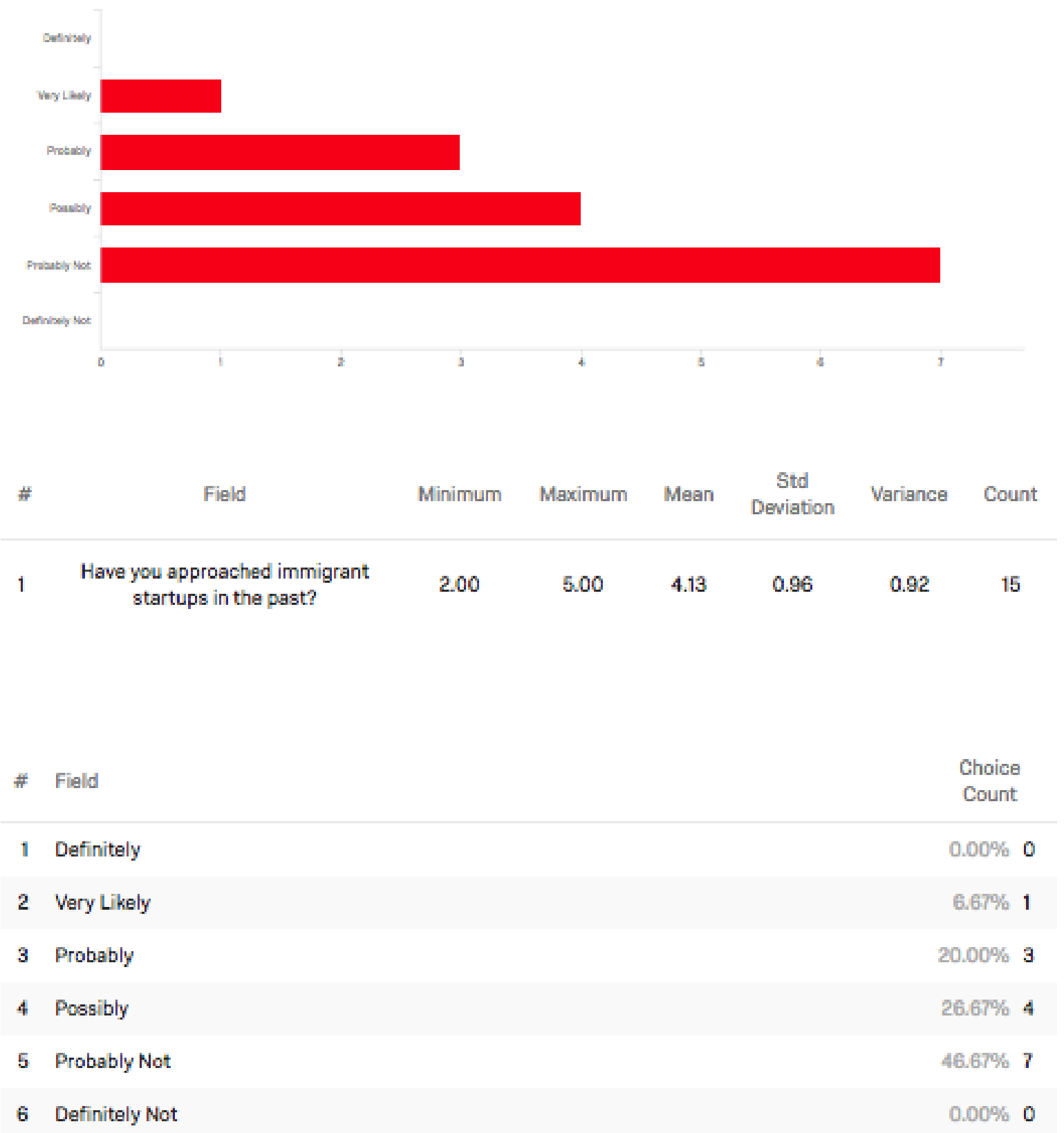




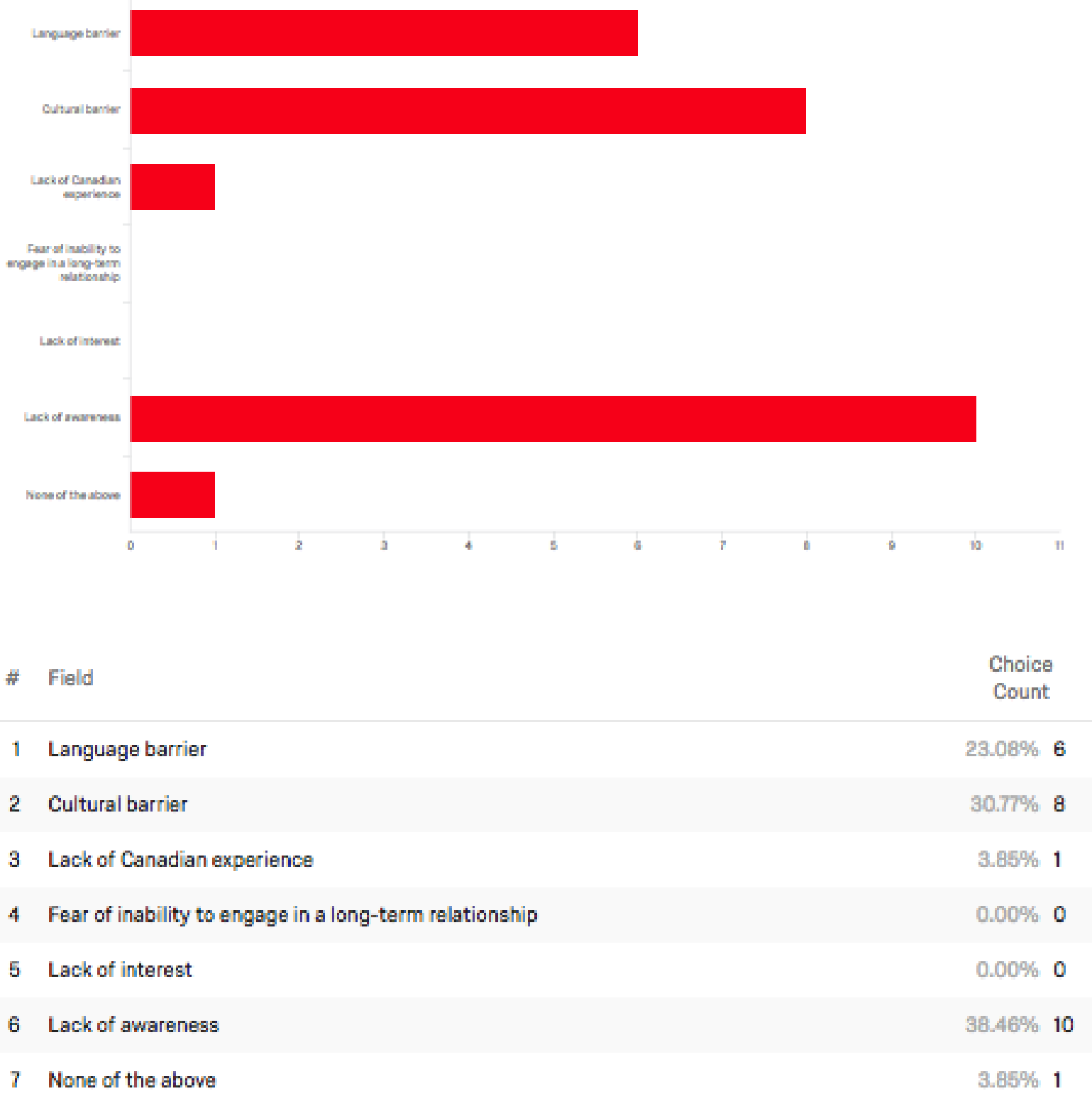




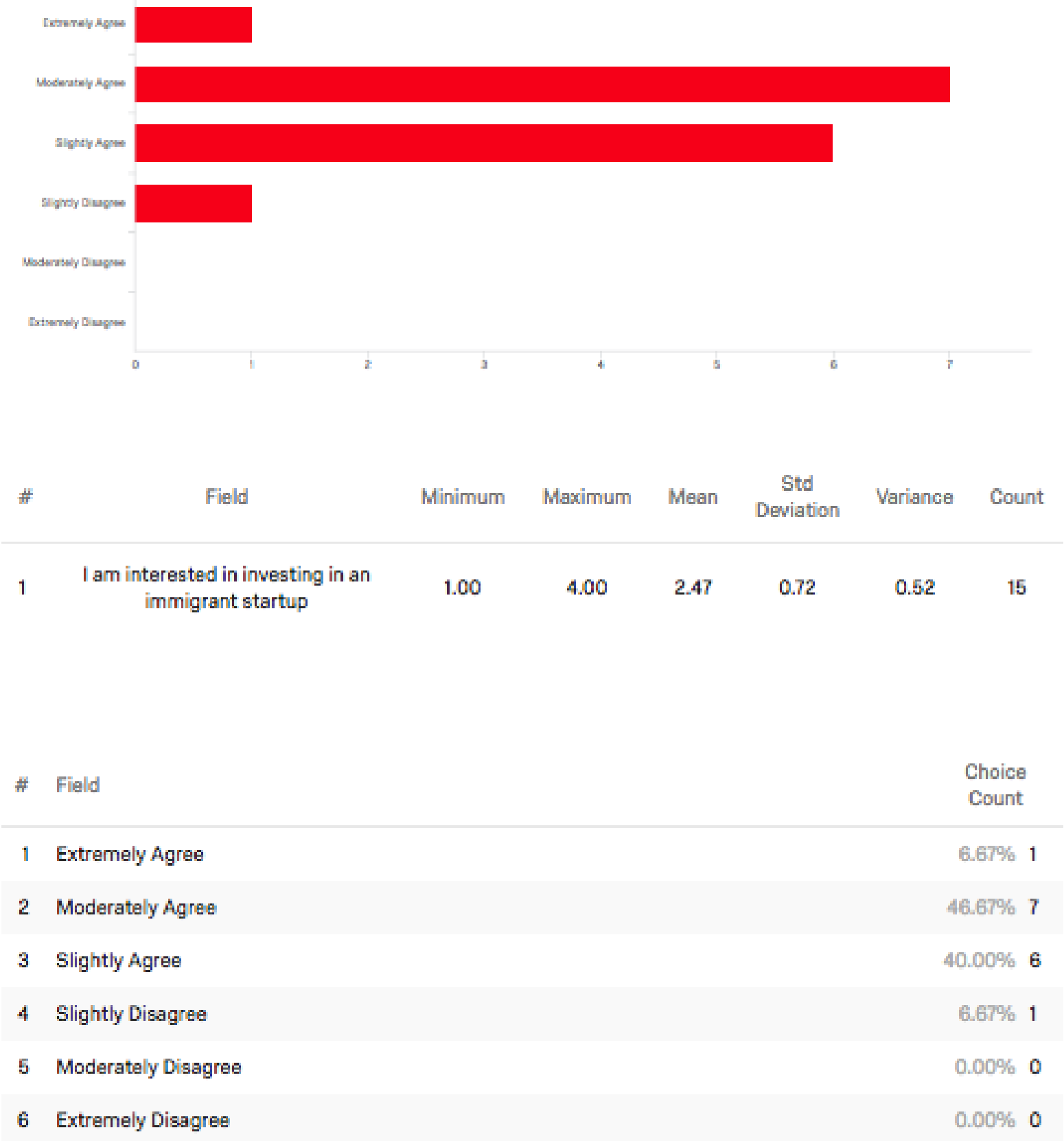




\section{Immigrant Startup's Engagement with Angels}

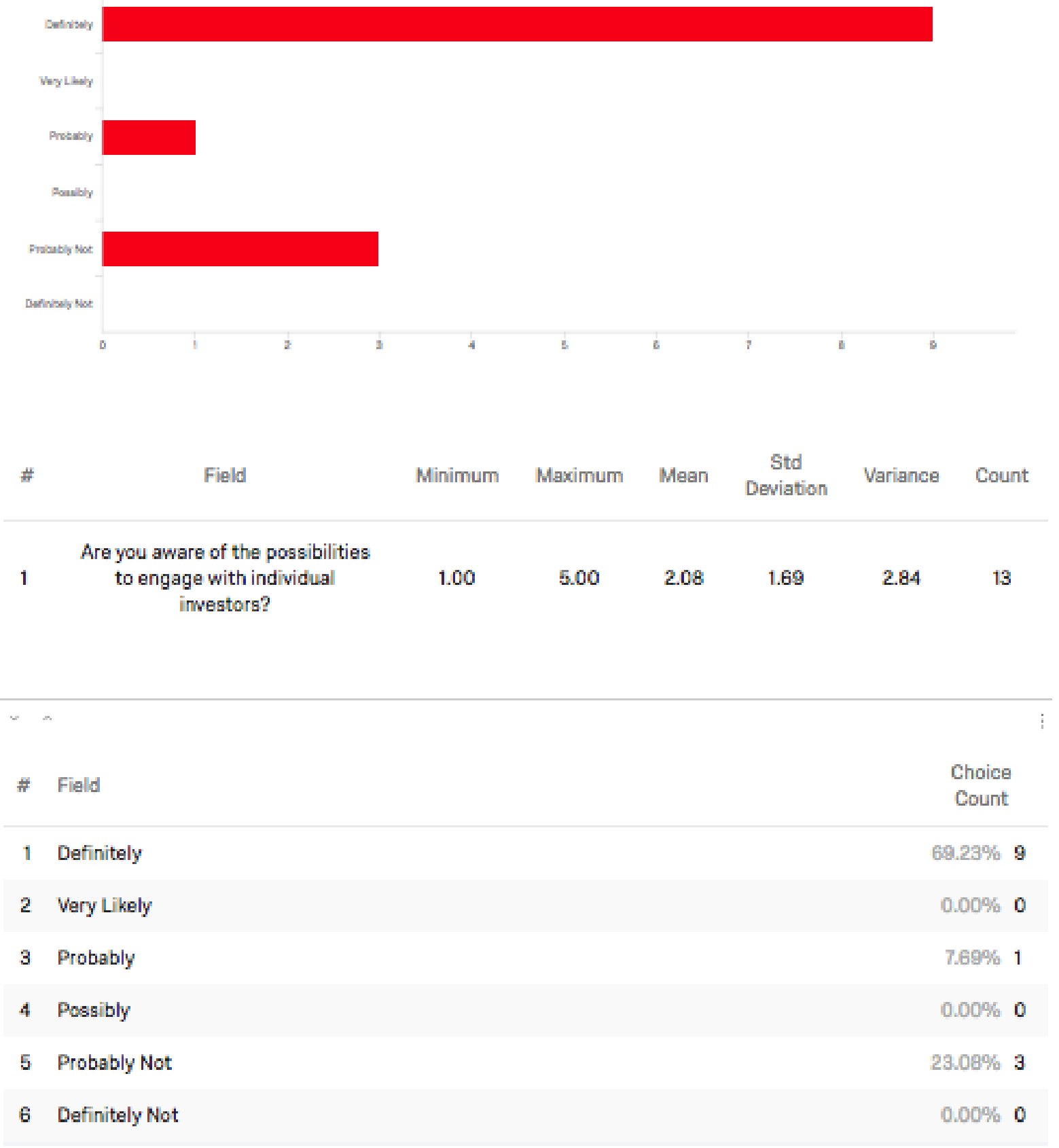




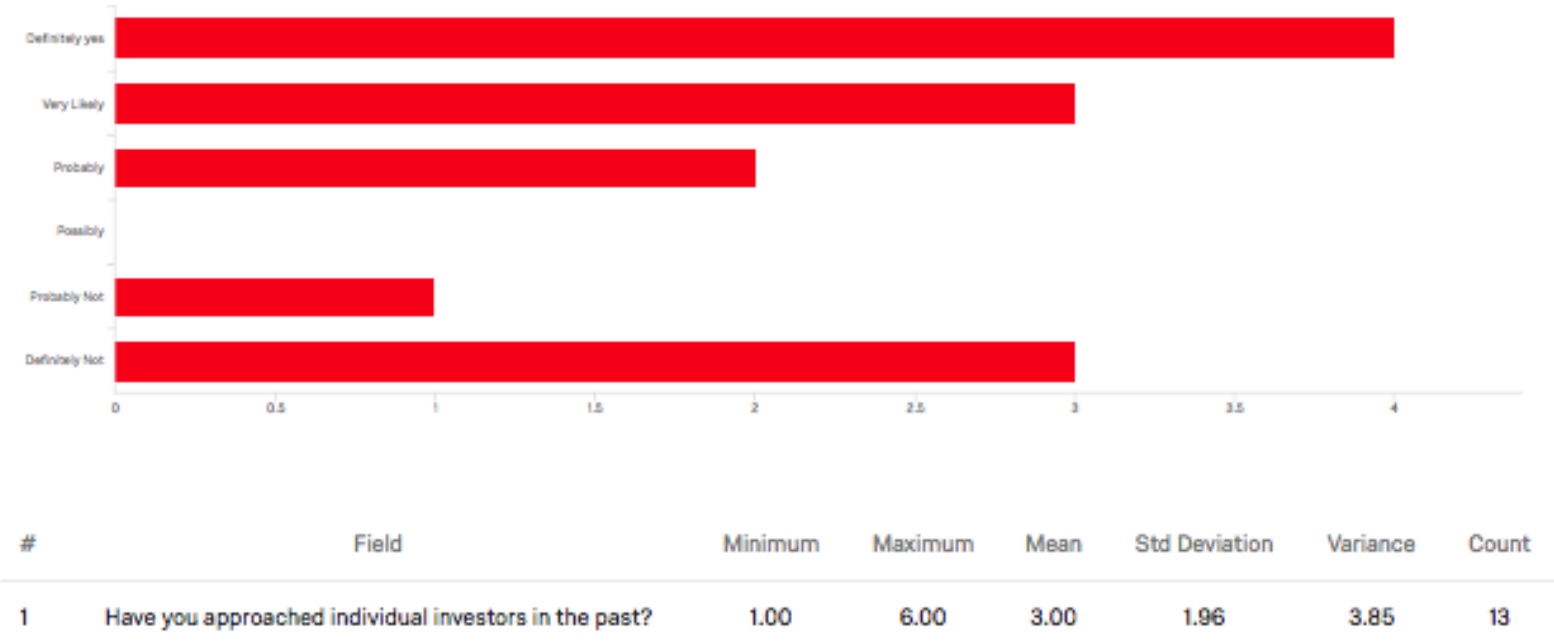

\begin{tabular}{|c|c|c|}
\hline & Field & $\begin{array}{l}\text { Choice } \\
\text { Count }\end{array}$ \\
\hline 6 & Definitely Not & $23.08 \% 3$ \\
\hline 1 & Definitely yes & $30.77 \% \quad 4$ \\
\hline 4 & Possibly & $0.00 \% \quad 0$ \\
\hline 3 & Probably & $15.38 \% 2$ \\
\hline 5 & Probably Not & $7.69 \% 1$ \\
\hline 2 & Very Likely & $23.08 \% 3$ \\
\hline
\end{tabular}




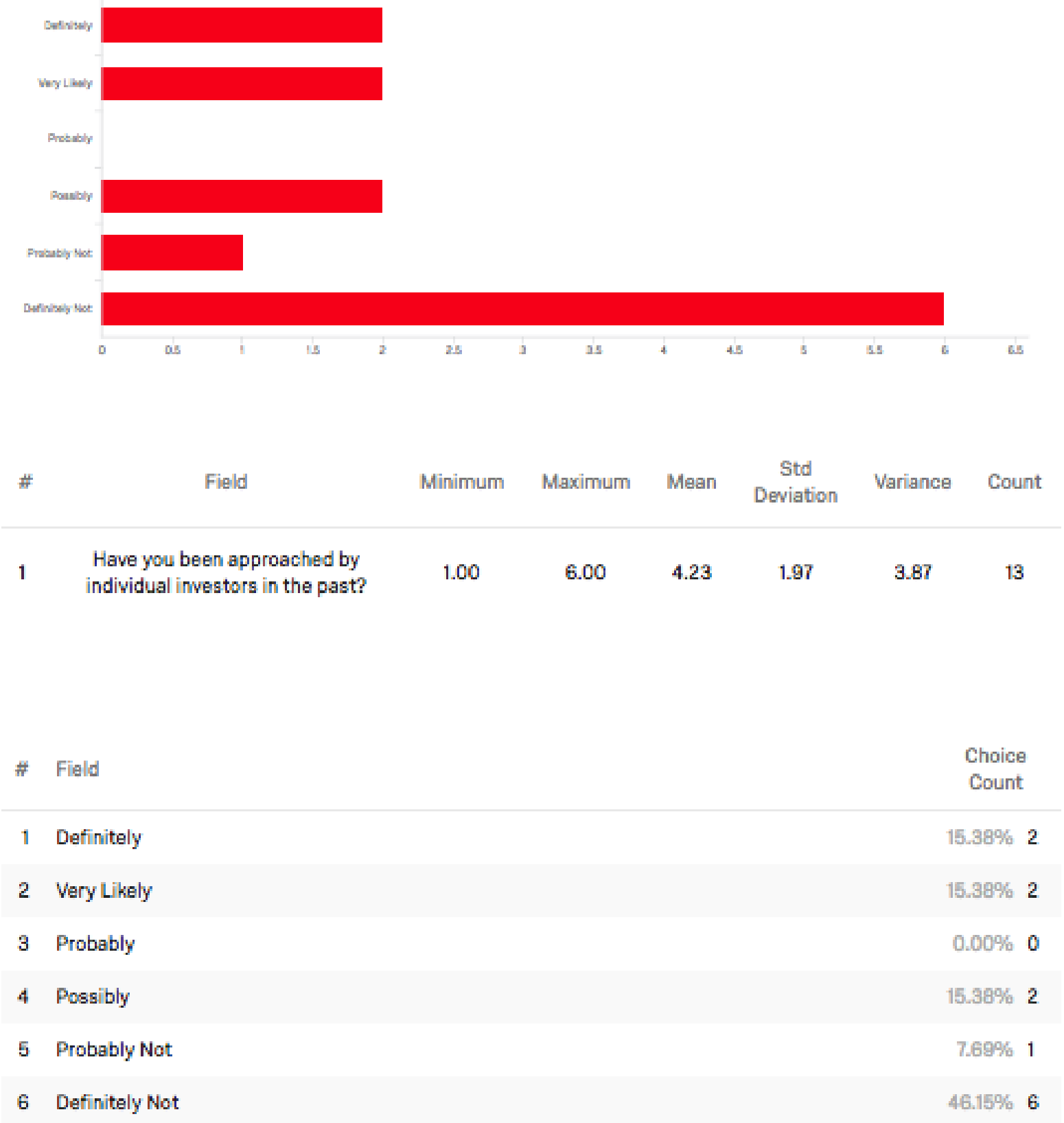




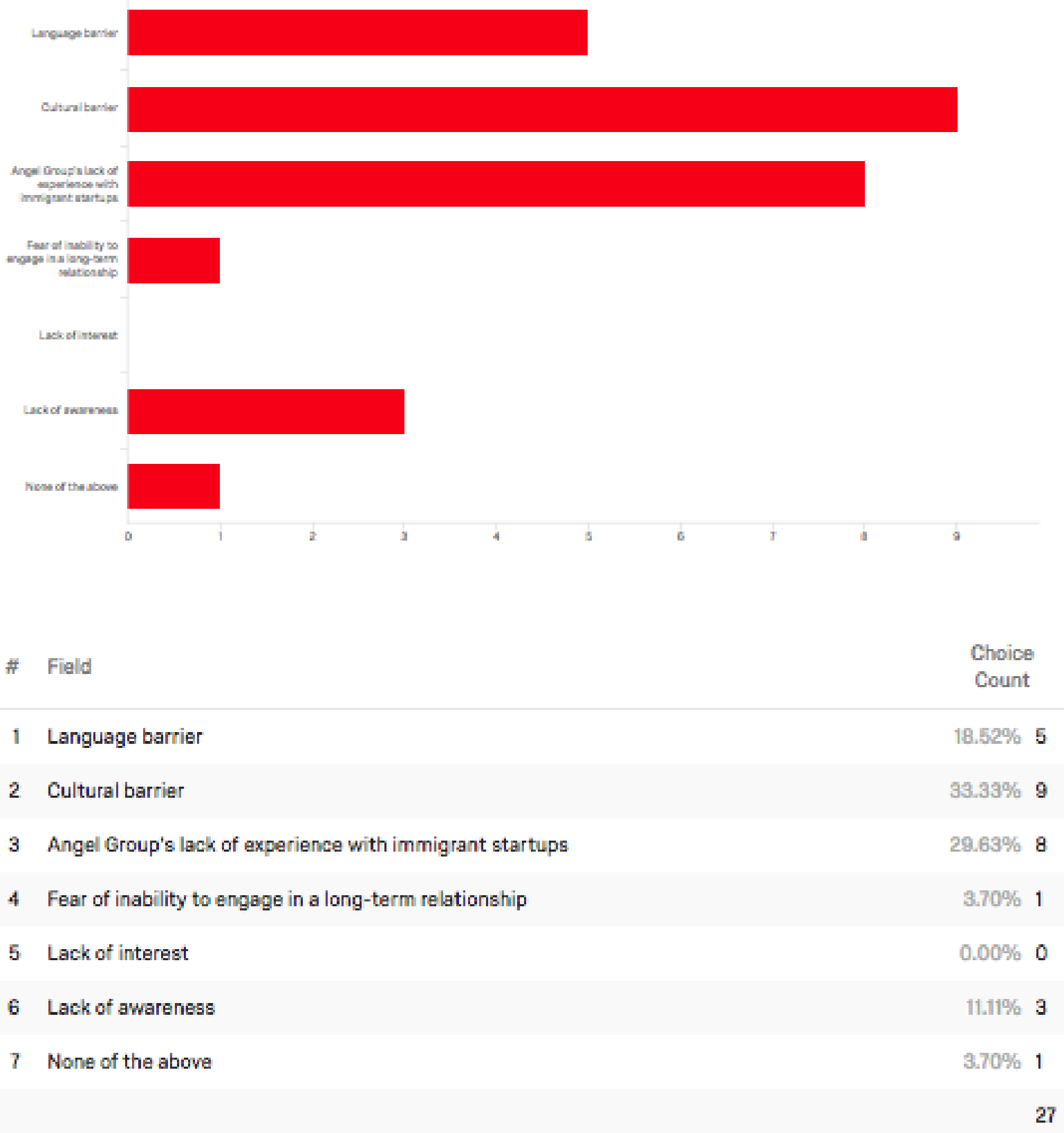




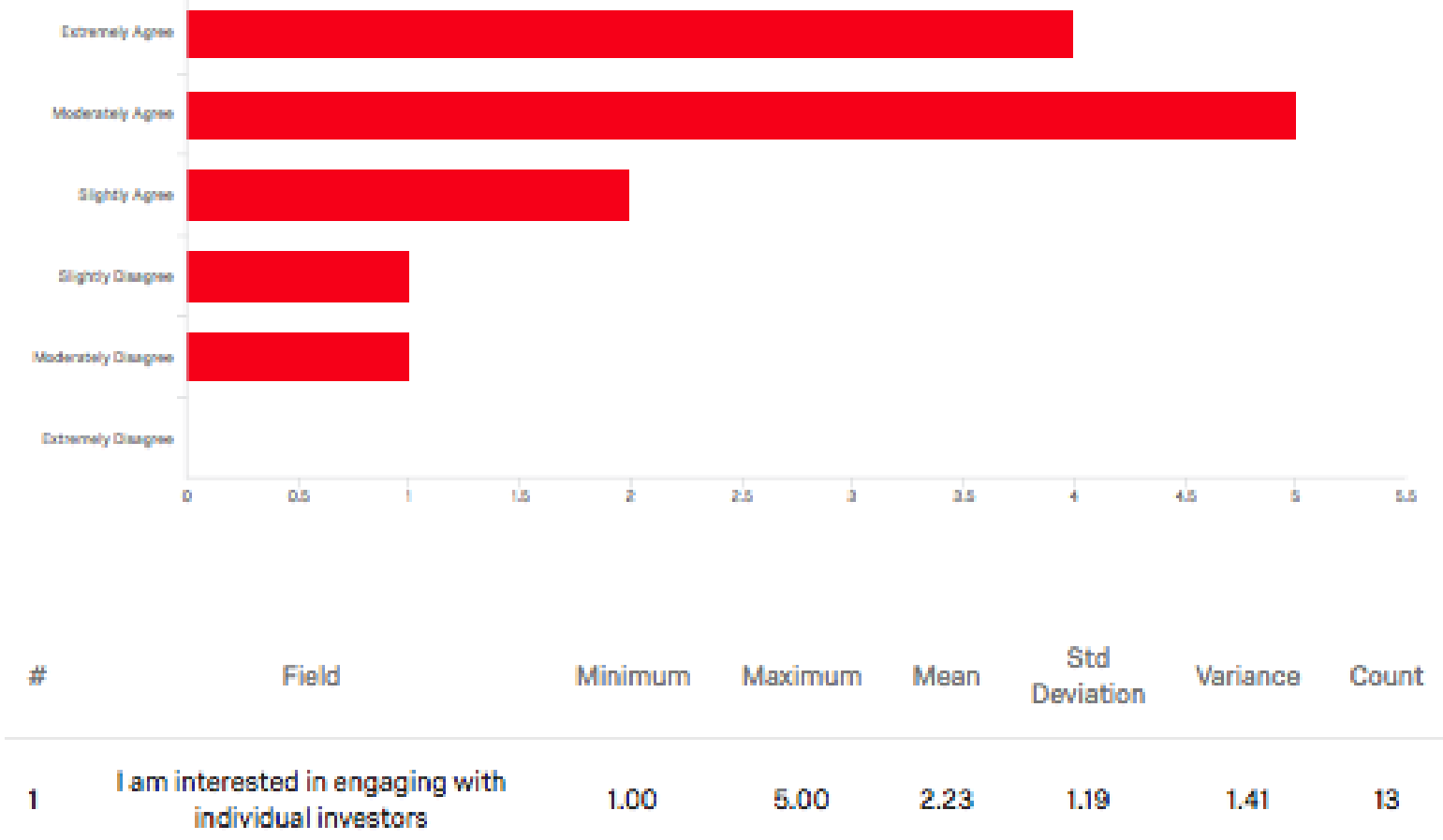

\begin{tabular}{|c|c|c|}
\hline \# & Field & $\begin{array}{l}\text { Choice } \\
\text { Count }\end{array}$ \\
\hline 1 & Extremely Agree & $30.77 \% \quad 4$ \\
\hline 2 & Moderately Agree & $38.46 \% 5$ \\
\hline 3 & Slightly Agree & $15.38 \% 2$ \\
\hline 4 & Slightly Disagree & $7.69 \% 1$ \\
\hline 5 & Moderately Disagree & $\begin{array}{lll}7.69 \% & 1\end{array}$ \\
\hline 6 & Extremely Disagree & $0.00 \% \quad 0$ \\
\hline
\end{tabular}




\section{References}

Bajwa, A. (2018). How Can We Predict the Success of immigrant Entrepreneurs in Canada? The Conference Board of Canada. Retrieved from https://www.conferenceboard.ca/commentaries/immigration/default/hot-topics-inimmigration/2018/07/16/how-can-we-predict-the-success-of-immigrantentrepreneurs-in-canada?AspxAutoDetectCookieSupport=1

Bammens, Y., \& Collewaert, V. (2013). Trust between Entrepreneurs and Angel Investors. Exploring Positive and Negative Implications for Venture Performance Assessments. Journal of Management, 50 (6): 1070-1096.

Bathelt, H., \& Spiegel, B. (2015). University spin-offs, entrepreneurial environment and start-up policy: the cases of Waterloo and Toronto (Ontario) and Columbus (Ohio). International Journal of Knowledge-Based Development.

Benjamin, G.A., \& Margulis, J. (2000). Angel Financing: How to Find and Invest in Private Equity. John Wiley \& Sons, New York, NY.

Bonini, S. (2018). Angel Network Affiliation and Business Angels' Investment Practices. Journal of Corporate Finance, 50: 592-608.

Carpenter, R.E., \& Petersen, B.C. (2002). Capital market imperfection, high-tech investment and new equity financing. Journal of Economics, 112(477). F54-F72.

Carpentier, C., \& Suret, J.M. (2015) Angel group members' decision process and rejection criteria: A longitudinal analysis. Journal of Business Venturing, 808-821.

Dalziel, M. (2008). Immigrants as extraordinarily successful entrepreneurs: A pilot study of the Canadian experience. Journal of Small Business and Entrepreneurship, 21(1), 2336.

Delmar, F., \& Shane, S. (2006). Does experience matter? The effect of founding team experience on the survival and sales of newly founded ventures. Strategic Organization, 4(1), 215-47.

Ding, Z., Sun, S.L. \& Au, K. (2011). Angel investors' selection criteria; A comparative institutional perspective. Asia Pacific Journal of Management, 205-231.

Durufle, G. (2009). Why Venture Capital is Essential to the Canadian Economy: The Impact of Venture Capital on the Canadian Economy. Canada's Venture Capital \& Private Equity Association, 5-46.

Dutta, S., \& Folta, T. B. (2016). A comparison of the effect of angels and venture capitalists on innovation and value creation. Journal of Business Venturing, 31(1), 39-54.

Elie, C., \& Arcand S. (2009). Survival of Necessity Immigrant Entrepreneurs: An

Exploratory Study. Journal of Comparative International Management, 12.2: 3-29. 
Erdman, K. M. (2017). An analysis of geert hofstede's culture's consequences: Comparing values, behaviors, institutes and organizations across nations. Macat International Ltd.

Farrell, A. E. (2005) Motivations, behaviour and cognition of novice and habitual business angels in new firm incorporations. University of Nottingham.

Feeney, L., Haines, G.H., \& Riding, A.L. (1999). Private investors' investment criteria: Insights from qualitative data. Venture Capital, 1(1), 121-145.

Florin, C. (2013). Evaluation and Due Diligence of Business Angels Investments. Commission for Technology and Innovation, 1-75.

Gignac, C. (2013). For Canada, immigration is a key to prosperity. The Globe and Mail. Retrieved from https://www.theglobeandmail.com/report-onbusiness/economy/economy-lab/for-canada-immigration-is-a-key-toprosperity/article14711281/

Glaser, R. (1984). Education and thinking: The role of knowledge. American Psychologist. 39(2), 93-104.

Golob, M. I., \& Giles, A. R. (2017). Immigrant entrepreneurship in Canada: Sites for cultural preservation, inclusion, and community development. Journal of Multicultural Discourses, 12(1), 27-41.

Gomez, C., Perera, B. Y., Weisinger, J. Y., Tobey, D. H., \& Zinsmeister-Teeters, T. (2015). The impact of immigrant entrepreneurs' social capital related motivations. New England Journal of Entrepreneurship, 18(2), 19-30.

Granovetter, M. (1985). Economic Action and Social Structure: The Problem of Embeddedness. American Journal of Sociology. 91(3), 481- 510.

Haines, G.H. Jr, Madill, J.J., \& Riding, A. (2003). Informal investment in Canada: Financing small business growth. Journal of Small Business and Entrepreneurship. $16(3-4), 13-40$.

Hagglund, K., \& Riding, A. (2009). Complementarities between Canadian Venture Capital Firms and Business Angels (Summary). Frontiers of Entrepreneurship Research, 29(2), Article 6. Retrieved from https://digitalknowledge.babson.edu/fer/vol29/iss2/6

Harrison, R.T., Mason, C.M. (2008). Sampling and data collection in business angel research. An International Journal of Entrepreneurial Finance. 305-308.

Harrison, R.T., Mason, C.M, Smith. (2015). Heuristics, learning and the business angel investment decision-making process. An International Journal, 527-554.

Harroch, R. (2015). 20 Things All Entrepreneurs Should Know About Angel Investors. Forbes. Retrieved from: https://www.forbes.com/sites/allbusiness/2015/02/05/20things-all-entrepreneurs-should-know-about-angel-investors/\#193663cclaa5 
Head, K., \& Reis K. (1998). Immigration and Trade Creation: Econometric Evidence from Canada. Canadian Journal of Economics, 31(1), 47-62.

Herman, R.T., \& Smith, R.L. (2009) Why Immigrant Entrepreneurs Are Driving the New Economy. Immigrant, Inc.

Hesse-Biber, S. N. (2010). Mixed Methods Research: Merging Theory with Practice. The Guilford Press.

Holladay, J. W., Meltzer, S. L., \& McCormick, J. T. (2003). Strategies for attracting angel investors. Journal of Commercial Biotechnology, 9(2), 129-133.

Hudson, M. (2017). In-Depth Angel Investor Survey Sheds Light on Angel Success. Forbes. Retrieved from https://www.forbes.com/sites/mariannehudson/2017/12/01/indepth-angel-investor-survey-sheds-light-on-angel-success/\#a41d7ec7d359

Jeng, L.A., \& Wells, P.C. (2000). The determinants of venture capital funding: Evidence across countries. Journal of Corporate Finance, 6(3), 241-289.

Johnson, W.C., \& Soh, J. (2012). Angels and venture capitalists in the initial public offering market. Venture Capital, 14(1), 27-42.

Kahn, S., La Mattina, G. \& J. MacGarvie, M. (2017). "Misfits", "stars” and immigrant entrepreneurship. Small Business Economics, 49(3), 533-557.

Kaish, S., \& B. Gilad. 1991. Characteristics of opportunities search of entrepreneurs versus executives: Sources, interests, and general alertness. Journal of Business Venturing, $6(1), 45-61$.

Kelly, P., \& Hay, M. (1996). Serial investors and early stage finance. Journal of Entrepreneurial and Small Business Finance, 5(2), 159-174.

Kolodny, L. (2015). VC FOCUS: Venturing north: U.S. VCs explore Canada's start-up scene. The Private Equity Analyst.

Krueger JR, N. F., Reilly, M. D., \& Carsrud, A. L. (2000). Competing models of entrepreneurial intentions. Journal of Business Venturing, 15(5-6), 411-432.

Landstrom, H. (1993). Informal risk capital in Sweden and some international comparisons. Journal of Business Ventures, 8(6), 525-540.

Lange, J., Leleux, B., Surlemont, B. (2000). Angel Networks for the Twenty-first Century: An Examination of Practices of Leading Networks in Europe and the United States. 40-52.

Madill, J,, Haines, G.H., \& Riding, A.L. (2004). The Role of Angels in Technology SMEs: A link to Venture Capital. An International Journal of Entrepreneurial Finance, 107129 
Mason, C. \& Harrison, R. (2002). Barriers to investment in the informal venture capital sector. Entrepreneurship and Regional Development, 14 (3), 271-287.

Mason C.M. (2006) Informal Sources of Venture Finance: The Life Cycle of Entrepreneurial Ventures, International Handbook Series on Entrepreneurship, 3(1), 259-299.

Mason C.M. (2008) The Real Venture Capitalists: A Review of Research on Business Angels. Hunter Center for Entrepreneurship, 1-55.

Malmström, M. (2014). Typologies of Bootstrap Financing Behavior in Small Ventures. Venture Capital, 16(1), 27-50.

Maxwell, A. L., \& Lévesque, M. (2014). Business angel early stage decision making. Journal of Business Venturing, 212-225.

Maxwell, A. L., \& Lévesque, M. (2014). Trustworthiness: A critical ingredient for entrepreneurs seeking investors. Entrepreneurship Theory and Practice, 38(5), 10571080.

McMullen, J.S., \& Shepherd, D.A., (2006). Entrepreneurial action and the role of uncertainty in the theory of the entrepreneur. Academy of Management Review, 31 (1), 132-152.

Mitteness, C., Sudek, R., \& Cardon, M.S. (2012). Angel Investor Characteristics that Determine Whether Perceived Passion Leads to Higher Evaluations of Funding Potential. Journal of Business Venturing, 27(5), 592-606.

Mitteness, C.R., Sudek, R. "Horse Vs. Jockey? How Stage of Funding Process and Industry Experience Affect the Evaluations of Angel Investors." Venture Capital 14.4 (2012): 241-67.

Moghaddam, K. (2017). High-Growth Entrepreneurial Firm Funding: A Qualitative Study of Native-Born and Immigrant Entrepreneurs. Venture Capital, 19(1-2), 75-94.

Momani, B., \& St. Amand, S. (2014). Organizational culture, learning and structure in central banks best practices and the case of the Moroccan Central Bank. The Centre for International Governance Innovation.

NACO: National Angel Capital Organization. (2016). Investment Activity by Canadian Angel Groups: 2016 Report. National Angel Capital Organization, 1-20.

Neville, F. (2014). Do Young Firms Owned by Recent Immigrants Outperform Other? Young Firms? Journal of Business Venturing, 29(1), 55-71.

Newstex (2013). Small Business Trends: 5 Small Business Financing Options for Startup Entrepreneurs. Newstex Entrepreneurship Blogs.

Nicholson, P. (2009). Innovation and Business Strategy: Why Canada Falls Short. Council of Canadian Academies: International Productivity Monitor, 51-71. 
Osnabrugge, M.V., \& Robinson, Rj.J. (2000). Angel Investing: Matching Start-up Funds with Start-up Companies. Business and Economics, 1-448.

Ostrovsky, Y., \& Picot, G. (2018). Research Blog: Immigrant entrepreneurs in Canada. Stantistics Canada. Retreived from https://www.statcan.gc.ca/eng/blog/cs/immigrantentrepreneurs

Rendell, M. (2017). Initiative launches to support more diverse Canadian entrepreneurship. The Globe and Mail. Retrieved from https://www.theglobeandmail.com/report-on-business/initiative-launches-to-supportmore-diverse-canadian-entrepreneurship/article35312131/

Riding, A.L. (2008). Business angels and love money investors: segments of the informal market for risk capital. An International Journal of Entrepreneurial Finance, 355369.

Ronstadt, R. (1988). The corridor principle. Journal of Business Venturing, 3(1), 31-40.

Sarooghi, H., Libaers, D., \& Burkemper, A. (2015). Examining the relationship between creativity and innovation: A meta-analysis of organizational, cultural, and environmental factors. Journal of Business Venturing, 30(5), 714-731.

Sim, D. (2015). Immigrant Entrepreneurship in Canada: A scan of the experience of Canadian immigrant entrepreneurs, and policy and programs for encouraging immigrant business. Global Diversity Exchange. (1-17). Retrieved from http://www.hireimmigrants.ca/wpcontent/uploads/Immigrant_Entrepreneurship_Canada.pdf

Singer, M. (1998). Expected socioeconomic impacts of entrepreneur immigrants from the newly industrialized economies: The role of personal contact and culture-stereotypic attitudes. Journal of Social Behavior and Personality, 13(4), 697.

Spence, M.T., \& M. Brucks, M. (1997). The moderating effects of problem characteristics on experts' and novices' judgments. Journal of Marketing Research, 34(2), 233-47.

Spence, Rick. (2017). AngelList brings angels to entrepreneurs (on a deadline). Financial Post. Retrieved from https://business.financialpost.com/entrepreneur/money/angellistbrings-angels-to-entrepreneurs-on-a-deadline

Stedler, H., \& Peters, H. H. (2003). Business Angels in Germany: An empirical study. Venture Capital, 5(3), 269-276.

Steier, L., \& Greenwood, R. (2000). Entrepreneurship and the Evolution of Angel Financial Networks.

Stel, A. Van, Carree, M., \& Thurik, R. (2005). The Effect of Entrepreneurial Activity on National Economic Growth. Small Business Economics, 24(3), 311-321. Retrieved from https://doi.org/10.1007/s11187-005-1996-6 
Sudek, R. (2007). Angel Investment Criteria. Journal of Small Business Strategy, 17(2), 89103.

Sudek, R. (2007). Investigating the Angel Funding Process: How Entrepreneur Enthusiasm, Trustworthiness and Venture Attributes Affect Angel Investment Decision Processes, The Claremont Graduate University.

Tan, J., Zhang, H., \& Wang, L. (2015). Network closure or structural hole? The conditioning effects of Network-Level social capital on innovation performance. Entrepreneurship Theory and Practice, 39(5), 1189-1212.

Teixeira, C. (2011). Community Resources and Opportunities in Ethnic Economies: A Case Study of Portuguese and Black Entrepreneurs in Toronto. Urban Studies, 38(11), 2055-78.

Tesfom, G., \& Lutz, C. (2009). Immigrant entrepreneurs challenging conventional wisdom: The adherence to immigrant networks plays a minor role in business success. International Journal of Entrepreneurship and Small Business, 8(2), 241-258 Retrieved from https://doi.org/10.1504/IJESB.2009.024379

Van Osnabrugger, M. \& Robinson, \& R.J. (2000). Angel investing: matching start-up funds with start-up companies: the guide for entrepreneurs, individual investors, and venture capitalist. San Francisco: Joseey-Bass.

Ward, S. (2018). What Is a Venture Capitalist?. Small Business. Retrieved from https://www.thebalancesmb.com/what-is-a-venture-capitalist-2947071

Wei-dong, Z., \& Zhang, W. (2008). Subjective Assessment by Entrepreneurs and Venture Financing for Startup Enterprises.

Whittam, G. (2010). Business Angel Syndicate: An Exploratory Study of Gatekeepers. An International Journal of Entrepreneurial Finance. 2

Wiltbank, R., Sudek, R., \& Read, S. (2009). The Role of Prediction in New Venture Investing. Retrieved from http://ezproxy.lib.ryerson.ca/login?url=https://searchproquest

Zu Knyphausen-Aufseß, D., \& Westphal, R. (2008). Do business angel networks deliver value to business angels? Venture Capital, 10(2), 149-169. 